\title{
Quantifying the dynamics of the interannual variabilities of the wintertime East Asian Jet Core
}

\author{
Duo Chan ${ }^{1,2} \cdot$ Yang Zhang ${ }^{1}$ (I) $\cdot$ Qigang $\mathrm{Wu}^{3} \cdot$ Xianglin Dai $^{1}$
}

Received: 4 July 2019 / Accepted: 8 January 2020 / Published online: 23 January 2020

(c) The Author(s) 2020

\begin{abstract}
The East Asian jet has evident interannual variability in strength and position and has broad impacts on weather and climate in the Asian-Pacific-American region. In this study, we quantify the relative contributions of distinct dynamical processes responsible for the wintertime interannual variability of the East Asian jet core. The quantification is based on analyzing the zonal momentum budgets. Our budget analyses show distinct up- and downstream controls for the interannual intensification of the jet. Over the upstream, the jet intensification is predominantly driven by enhanced upper-level angular momentum transport associated with local convective-driven Hadley-cells. In addition to convections over the Tropical Pacific, those over the Bay of Bengal-South China Sea are found responsible for a distinct local Hadley cell over $80^{\circ}-100^{\circ} \mathrm{E}$, which accelerates the jet from its very upstream. Over the downstream, angular momentum advected by the mean flow from the upstream is the first-order term responsible for the jet intensification, whereas synoptic eddies play a secondary role. For the interannual meridional displacement of the jet, synoptic eddy activities over the North Pacific are found to contribute predominantly. For both the intensification and the meridional displacement, the upper-tropospheric jet covaries closely with changes in the Subtropical Oceanic Frontal Zone in the North Pacific. Such a strong covariation implies the contributions of the air-sea interactions to the downstream jet variability.
\end{abstract}

\section{Introduction}

The East Asian jet, which refers to the strong and narrow upper tropospheric westerly belt over extratropical East Asia and North Pacific as shown in Fig. 1, is an important atmospheric circulation system in Asian-Pacific region. It is a crucial component of the East Asian monsoon system, and the seasonal evolution of the East Asian jet reflects the seasonal transition of regional atmospheric circulations (Yeh et al. 1959; Liang and Wang 1998; Zhang et al. 2008; Schiemann et al. 2009; Ren et al. 2010; Wang and Lu 2017; Chowdary et al. 2019). The East Asian jet is also associated closely with other synoptic phenomena, e.g., cyclogenesis,

Yang Zhang

yangzhang@nju.edu.cn

1 CMA-NJU Joint Laboratory for Climate Prediction Studies, School of Atmospheric Sciences, Nanjing University, Nanjing, China

2 Department of Earth and Planetary Sciences, Harvard University, Cambridge, USA

3 School of Atmospheric Sciences, Fudan University, Shanghai, China frontogenesis and extreme high- or low-temperature events (Palmén and Newton 1969; Shapiro and Keyser 1990; Gao and Tao 1991; Wang et al. 2013; Liao and Zhang 2013).

Many previous studies have shown that the wintertime East Asian jet is characterized with evident interannual variabilities in strength and position, which has broad impacts on the weather and climate in Asian-Pacific-American region. The study by Yang et al. (2002) revealed the strong interannual variability in the intensity of the wintertime East Asian jet. In winter, an enhanced East Asian jet is often associated with a stronger Aleutian low and Siberian high, as well as a strengthened mid-tropospheric East Asian trough (Yang et al. 2002; Jhun and Lee 2004; Li and Yang 2010). The intensified East Asian jet can also affect the Pacific-NorthAmerica stationary wave pattern (Athanasiadis et al. 2011; $\mathrm{Li}$ and Wettstein 2012), which leads to temperature and precipitation anomalies from the upstream East Asia to the downstream North America (Yang et al. 2002). In addition to its intensity, the East Asian jet exhibits evident interannual variability in its latitudinal position as well (Ren et al. 2008; Athanasiadis et al. 2011; Ren et al. 2011). The meridional displacement of the East Asian jet is connected to the Western Pacific teleconnection, which can affect temperature 
Fig. 1 Climatology of the wintertime East Asia jet. a 200 hPa zonal-wind (contour lines; interval: $10 \mathrm{~ms}^{-1}$ ). Shown climatology is the DJF mean averaged over 1979-2017 using the ERA-interim reanalysis. Solid lines denote westerlies and dashed lines denote easterlies; zeros lines are omitted. The East Asian jet has maximum wind speed up to $70 \mathrm{~ms}^{-1}$ around its core. We define jet indices in the red box, which is small enough to focus on the core variability but is also large enough to contain all DJF mean jet axes in individual years (gray lines). b Schematics of meridional circulation for the climatological East Asian jet over the upstream of the jet. c is the same as b but over the downstream of the jet. Circulations indicate the zonal averages over $100^{\circ}-130^{\circ} \mathrm{E}$ for the upstream and over $140^{\circ}-200^{\circ} \mathrm{E}$ for the downstream

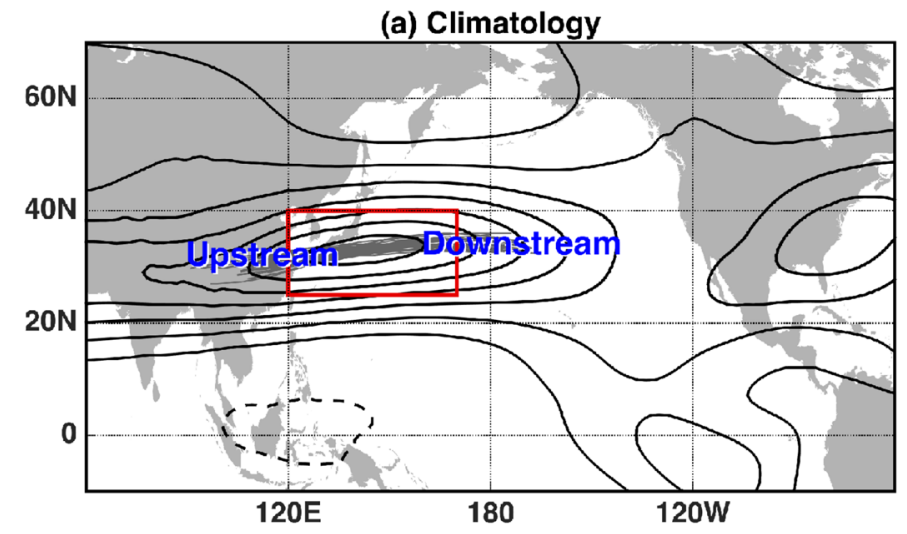

$\begin{array}{ll}\text { (b) Upstream }\left(100-130^{\circ} \mathrm{E}\right) & \text { (c) Downstream }\left(140-200^{\circ} \mathrm{E}\right)\end{array}$

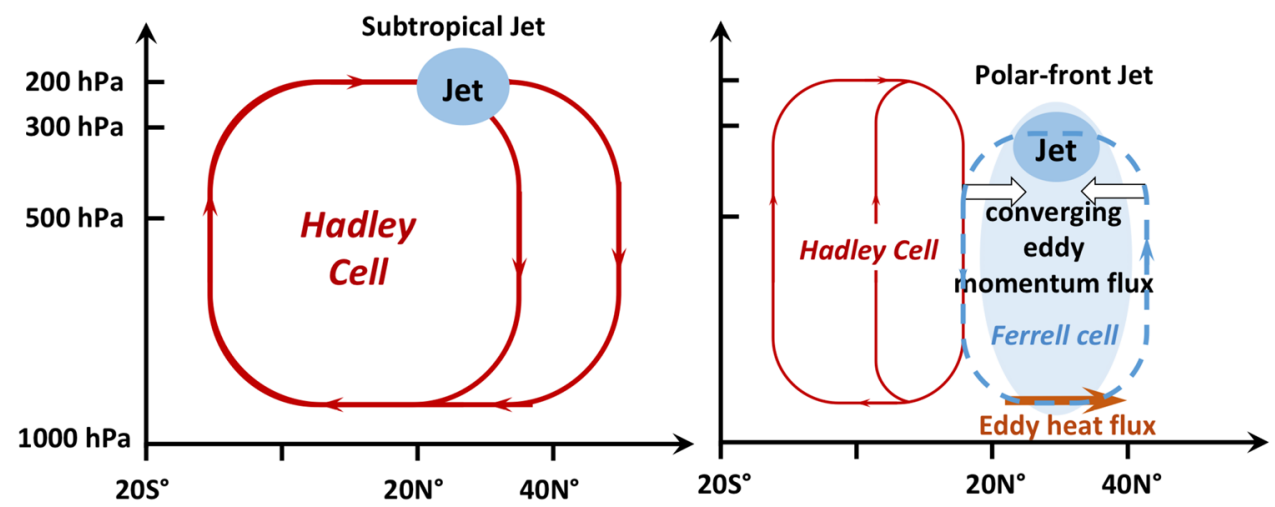

over the entire Southeastern China (Cheung and Zhou 2016) and rainfall along the Pacific coast from Alaska to northern California (Athanasiadis et al. 2011). Therefore, understanding the variability of the East Asian jet is important for both regional weather forecasting and climate predictions.

Even though the interannual variability of the East Asian jet and its impacts on weather and climate have been studied extensively, the dynamical mechanisms that are responsible for the year-to-year variability remain not fully understood. Many processes have been proposed to contribute. The theoretical study by Lee and Kim (2003) suggested that the westerly jet in the extra-tropics can be driven by two distinct dynamical processes. Jets can be driven by the upper-tropospheric angular momentum transport from the deep tropics (Held and Hou 1980; Lindzen and Hou 1988). This transport is accomplished through the thermally direct meridional overturning circulation (MOC, i.e., the Hadley cell). A jet driven by this process situates at the poleward boundary of the overturning circulation and is, therefore, referred to as the subtropical jet. In contrast to the MOC, jets can also be driven by synoptic transient eddies. The momentum flux convergence induced by synoptic eddies can cause strong westerlies throughout the whole troposphere (Held 1975; Panetta 1993). The synoptic transient eddies, which are primarily triggered from the baroclinic instability, are most active in the midlatitude baroclinic zone, and a jet driven by this process is referred to as the eddy-driven jet or midlatitude (polar-front) jet. In Asian-Pacific region, the latitude of strongest baroclinicity collocates with that of the subtropical jet during cold seasons, and the East Asian jet could be both eddy-driven and MOC driven (Lee and Kim 2003). Further analysis show that synoptic eddy activities help to maintain both the intensification (e.g., Yang et al. 2002; Wettstein and Wallace 2010) and the meridional shift of the jet (e.g., Wettstein and Wallace 2010; Ren et al. 2011; $\mathrm{Li}$ and Wettstein 2012). Moreover, intensified adiabatic heating averaged over the entire tropical Pacific are found to enhance the local Hadley cell thus elongate the jet ( $\mathrm{Li}$ and Wettstein 2012). Though different processes are shown to be associated with the interannual variations of the East Asian jet, their relative contribution to the jet variabilities remains unanswered.

The difficulties in revealing the mechanism of the interannual jet variability also lie in the distinct upstream and downstream dynamics of the East Asian jet. As shown in Fig. 1 , in the upstream region $\left(100^{\circ}-130^{\circ} \mathrm{E}\right.$, which is to the west of the jet core), the wintertime East Asian jet is closely associated with the local meridional circulation (local Hadley Cell). In climatology, the ascending motion of the meridional circulation locates above the Pacific Warm 
Pool, an area with active convections and the warmest sea surface temperature. The descending motion of the local meridional circulation expands over the entire midlatitude. The East Asian jet sits at the side of the descending branch of the circulation, more like a subtropical jet, and is confined in the upper troposphere. In the downstream region $\left(140^{\circ}\right.$ $-200^{\circ} \mathrm{E}$, which is to the east of the jet core), the climatological pattern of the meridional circulation always exhibits two distinct cells. Whereas the tropics and subtropics are characterized by a confined local Hadley cell, the midlatitude is characterized by an eddy-driven local Ferrell cell. The downstream of the East Asian jet, which tilts towards the midlatitude over the North Pacific Ocean (Fig. 1), is more like an eddy-driven jet and penetrates through the whole troposphere. The different mechanisms in the upstream and downstream regions responsible for the inter-annual variabilities of the East Asian jet have not been clearly addressed yet.

In this study, we will quantify distinct dynamical processes that are responsible for the interannual intensification and meridional shift of the East Asian jet. Our quantification is based on examining the zonal momentum budget congruent with individual modes of variability and we aim to answer the following questions:

1. Are the interannual variabilities of the East Asian jet mainly eddy-driven or MOC-driven?

2. Are the upstream and downstream variabilities of the East Asian jet dominated by different processes?

3. In addition to the thermal forcing in tropical Pacific responsible to the variation of $\mathrm{MOC}$, does forcing in other regions also significantly contribute thus provide a potential source of predictability for the jet variabilities?

The structure of the paper is assigned as follows. Section 2 introduces the data and methodology used in the study. In Sect. 3, changes of the zonal momentum budget with the jet variabilities are analyzed, through which key dynamical processes responsible for the upstream and downstream jet variabilities are identified. Major sources of forcing for the jet variabilities are investigated by analyzing associated changes in the tropical convective proxies (i.e., outgoing long-wave radiation, precipitation, and convective available potential energy) and sea surface temperature (SST) fields. A discussion and summary is presented in Sect. 4.

\section{Data and methods}

\subsection{Data}

In this study, we use both monthly and 6-h data from the ERA-interim reanalysis (Dee et al. 2011) to quantify interannual variability of the East Asian jet core and diagnose contributions of distinct dynamical processes. Our analyses are based on 39 years of data that spans from 1979 to 2018 and is performed at $1^{\circ} \times 1^{\circ}$ resolution. More specifically, we use $200 \mathrm{hPa}$ monthly zonal wind to calculate jet indices and use monthly three-dimensional wind fields and the geopotential height field to compute the ageostrophic term and mean-flow advection in the zonal momentum budget. The 6-h three-dimensional wind fields are filtered by different frequency bands to compute accelerations of the zonal flow associated with eddy activities (see more details in Sect. 2.2). Besides wind fields, monthly outgoing long-wave radiation (OLR), precipitation, and convective available potential energy (CAPE) from ERA-interim are used to represent tropical convective activities. In addition, 1979-2018 Japanese Oceanographic Data Center sea surface temperature version 2 (COBE-SST2; Hirahara et al. 2014), a monthly product at $1^{\circ}$ resolution, is used to examine the covariation of the surface baroclinicity.

The robustness of our results is confirmed by double checking our diagnostics using the National Center for Atmospheric Research/National Centers for Environmental Prediction (NCAR/NCEP) reanalysis (Kalnay et al. 1996), a dataset starting from 1948 but at $2.5^{\circ} \times 2.5^{\circ}$ resolution. We also check the Climate Prediction Center Merged Analysis of Precipitation (CMAP; Xie and Arkin 1997), a satellite and gauge based rainfall dataset spanning from 1979 to 2018, to confirm the results of tropical convective activities. We check SST fields in the ERA-interim reanalysis as well, which is a prescribed lower boundary condition combining several sources of SST analyses (Fiorino 2004). Analyses using those datasets all show consistent results, thus those analyses are not shown in the paper.

\subsection{Method}

\subsubsection{Intensity and latitudinal indices of the East Asian jet}

We define intensity (Int) and meridional displacement (Lat) indices to measure the interannual intensification and the poleward shift of the East Asian jet. Both indices are defined for the DJF-mean zonal wind at the $200 \mathrm{hPa}$ level (U200). The Int index is defined as the mean U200 over the climatological jet core region, which is similar to Yang et al. (2002). The jet core region is chosen to be $120^{\circ}-170^{\circ} \mathrm{E}$ and $25^{\circ}-40^{\circ} \mathrm{N}$ (red box region in Fig. 1a). The selection of the jet core region takes into account the time-mean distribution of U200 as well as the occurrence frequency of the maximum zonal wind. During the boreal winter, as shown in Fig. 1a, the climatological East Asian jet has zonally prolonged jet axis over East Asia and the Northwest Pacific. The maximum U200 is greater than 70 $\mathrm{ms}^{-1}$ and occurs over the ocean immediately to the south of Japan (around $32^{\circ} \mathrm{N}, 140^{\circ} \mathrm{E}$ ). The jet core region is chosen 
confined to the area of the strongest zonal wind speed. The selection of the jet core region also accounts for the distribution of the occurrence frequency of the maximum zonal wind. Figure 1a also plots the spatial distributions of the jet axis in each year. All of them occur in our defined jet core regions. Thus, our defined jet core region is also large enough to cover nearly all jet cores in individual years. It is, therefore, unlikely that a strengthened jet, whose center shifts away from the climatological jet core, is miscalculated with a weaker intensity.

The Lat index is defined as the latitude where the maximum U200 occurs most frequently. Because the jet axis of the East Asian jet is always zonally oriented as in Fig. 1a, the Lat index is estimated as the average latitude of jet axis over $120^{\circ}-170^{\circ}$ E. That is, we identify the latitude of maximum zonal wind at each longitude within the jet core region, and then compute the zonal average of these latitudes. The estimated Lat index can describe the meridional displacement of the whole jet axis of the East Asian jet.

Figure 2 shows the estimated two jet indices, which together captures more than $70 \%$ of variance over the jet core region. If an EOF analysis is performed over the jet core region, the first principal component explains $43 \%$ of total variance, and its correlation with our Int index is 0.98 . Similarly, the second principal component explains $33 \%$ of total variance, and its correlation with our Lat index is 0.90 . It is important to note that our jet indices mainly quantify the zonal wind variability over the jet core region. If the wind change is confined in the very up- or downstream of the jet, neither index will be able to capture that variability. It also worth noting that though mild inter-decadal variability in jet indices exists, the two indices primarily represent variabilities at the interannual timescale (Fig. 2). However, to focus on interannual variabilities, we apply an FFT filter to raw jet indices and remove the first three Fourier harmonics to obtain the interannual component of jet variabilities.

\subsubsection{Zonal momentum budget}

One important part of our work is the use of time-mean zonal momentum budgets to quantify contributions of different dynamical processes to the interannual variability of the East Asian jet. We start from the first equation of Eq. A10 in Hoskins et al. (1983), which is the time-mean equation describing the zonal motion of a Boussenisq, adiabatic fluid:

$\frac{D \bar{u}}{D t}=f \bar{v}-\bar{\phi}_{x}-\nabla \cdot\left(\overline{\mathbf{V}^{\prime} u^{\prime}}\right)$,

where $\mathbf{V}$ denotes a velocity vector, and $u$ and $v$ are the zonal and meridional wind speed, respectively. An over-bar denotes a time-mean quantity, and a prime denotes eddies deviating from the mean. On the left-hand-side, $\frac{D \bar{u}}{D t}$ denotes the material derivative of the time-mean zonal flow. On the right-hand-side, $f \bar{v}$ denotes the Coriolis force, $\bar{\phi}_{x}$ denotes the (a) Intensity index - Int

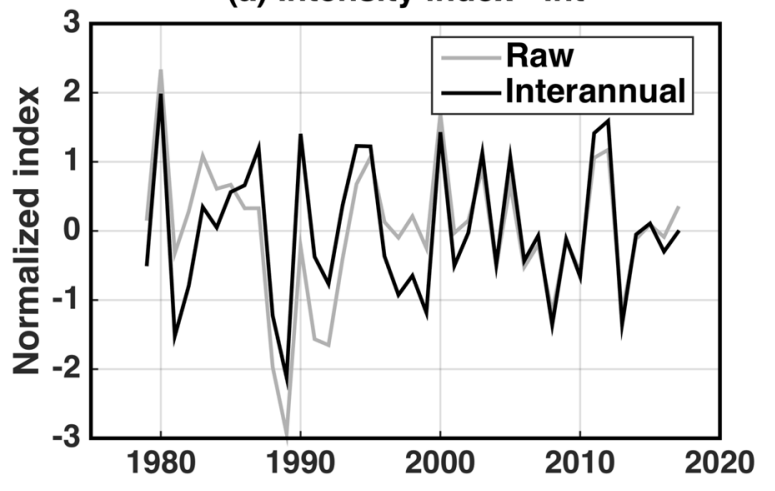

(b) Latitudinal position index - Lat

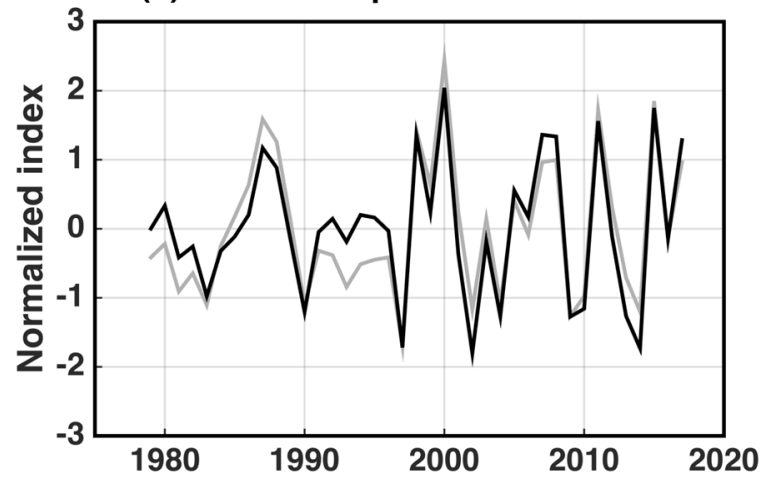

Fig. 2 Normalized East Asian jet indices, which show apparent interannual components. Shown indices are for a intensity (Int), which is the zonal-wind speed at $200 \mathrm{hPa}$ averaged over the red box in Fig. 1, and $\mathbf{b}$ latitudinal shifts (Lat), which is the mean latitude of jet axes over $120^{\circ}-170^{\circ} \mathrm{E}$. Gray lines are raw indices and black lines are interannual components. Regression analyses are based on black lines

pressure gradient force, and $\nabla \cdot\left(\overline{\mathbf{V}^{\prime} u^{\prime}}\right)$ denotes convergence of eddy momentum fluxes.

We rewrite Eq. (1) to diagnose zonal momentum budgets associated with the interannual variability of the East Asian Jet. First, $f \bar{v}$ and $\bar{\phi}_{x}$ are combined to an ageostrophic term, $f \bar{v}_{a}$, that represents the acceleration of zonal wind associated with meridional overturning circulations. Second, because many studies suggest that synoptic and lowfrequency eddies play distinct roles for jet variabilities (e.g., Hoskins et al. 1983; Leung and Zhou 2016), $\nabla \cdot\left(\overline{\mathbf{V}^{\prime} u^{\prime}}\right)$ is decomposed to represent contributions from synoptic and low-frequency eddies. Here, synoptic eddies are defined as variability whose frequency is higher than 10 days and are computed by applying a 10-day high-pass Lanczos filter (Emery and Thomson 2001) to 6-h wind fields. Similarly, low-frequency eddies have frequency between 10 and 90 days and are computed with a 10-90-day bandpass Lanczos filter. Cross-frequency interaction terms are neglected because of their small contributions. 
The equation used to diagnose zonal momentum budgets is:

$\frac{\partial \bar{u}}{\partial t}=f \bar{v}_{a}-(\overline{\boldsymbol{V}} \cdot \nabla) \bar{u}-\nabla \cdot\left(\overline{\mathbf{V}_{\mathbf{h}}^{\prime} u_{h}^{\prime}}\right)-\nabla \cdot\left(\overline{\mathbf{V}_{\mathbf{l}}^{\prime} u_{l}^{\prime}}\right)$.

The four terms on the right-hand side are ageostrophic acceleration associated with meridional overturning circulations, advection by the time-mean flow, and convergence of zonal-momentum fluxes through synoptic and low-frequency eddies, respectively. $v_{a}$ is the ageostrophic component of the meridional-wind. An over-bar denotes an average over DJF; subscripts $h$ and $l$ denote synoptic ( $<10$ days) and lowfrequency (10-90 days) eddy components, respectively. Regression of individual terms against a jet index reveals roles of distinct processes in driving the corresponding variability of the East Asian jet.

\section{Results}

\subsection{Zonal-wind responses at different heights}

Regression analyses are applied to U200 anomalies to verify the definition of the two jet indices (Fig. 3a, b). For both indices, regression patterns against normalized jet indices show stronger signals over the downstream of the climatological jet core, but wind responses are, in general, confined over East Asia-West Pacific, indicating the capability of our indices in capturing local features of the East Asian jet. For the Int index (Fig. 3a), compared with the climatological distribution of the East Asian jet, positive wind anomaly is found around the jet core region, relating to a strengthened jet. In addition to this positive center of wind anomaly, two zonally prolonged negative anomalies are found at jet flanks, implying that a meridional sharpening of jet occurs with a strengthened jet. These results are consistent with those of Yang et al. (2002), though the region used to define the Int index is larger in our study. Our results are also in general consistent with those from EOF analyses performed over a much bigger domain - the entire Pacific sector (Athanasiadis (a) Int - U200

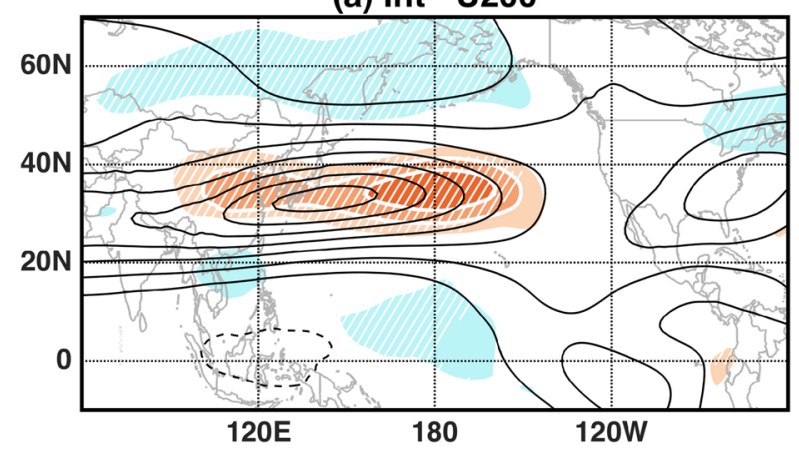

(c) Int - U850

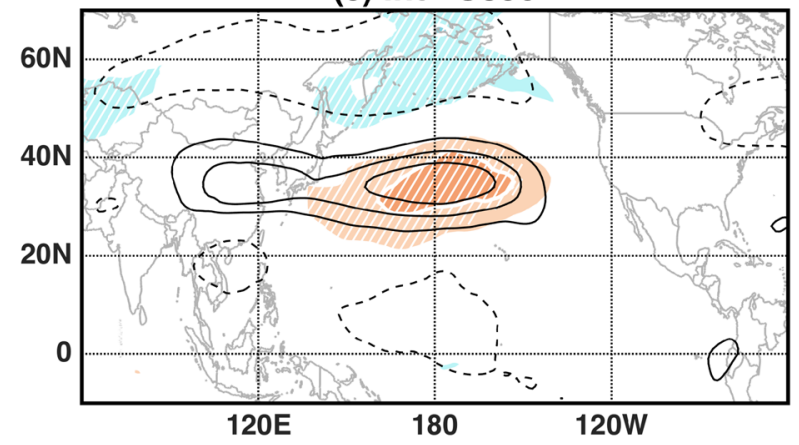

Fig. 3 Zonal-wind responses associated with normalized jet indices. Shown maps are regression patterns for a $200 \mathrm{hPa}$ zonal-wind on the Int index, b $200 \mathrm{~h} \mathrm{~Pa}$ zonal-wind on the Lat index, c $850 \mathrm{hPa}$ zonal-wind on the Int index, and $\mathbf{d} 850 \mathrm{hPa}$ zonal-wind on the Lat index. The two jet indices are well able to capture the intensification and poleward shift of the East Asian jet, and the zonal-wind response (b) Lat - U200

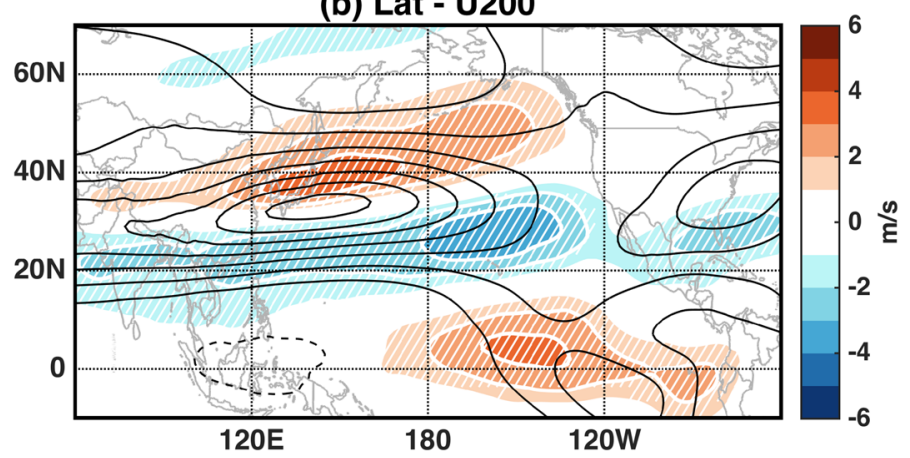

(d) Lat - U850

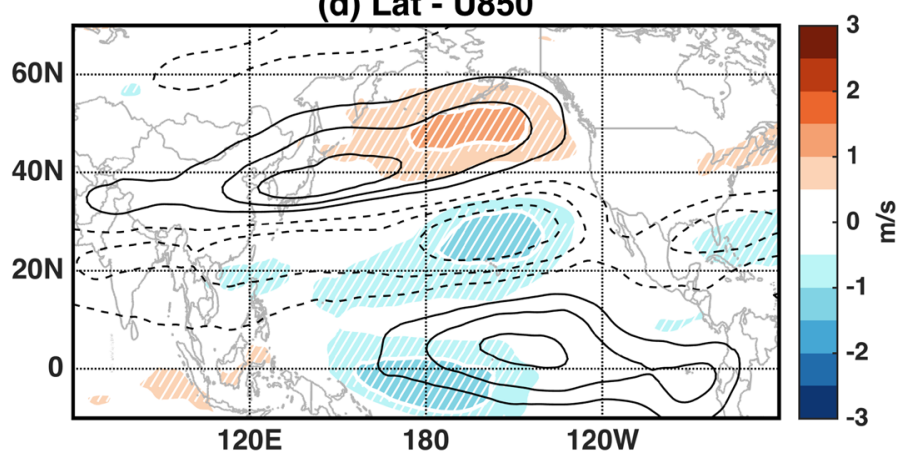

is more barotropic over the downstream region-central and eastern North Pacific. White shadings denote significant wind responses at the $90 \%$ level. Contour lines are the climatological $200 \mathrm{hPa}$ zonalwind for top panels, and are the $200 \mathrm{hPa}$ wind responses for bottom panels 
et al. 2011), though performing EOF over the whole North Pacific often yields more pronounced wind responses over the downstream region. When regressed against the Lat index (Fig. 3b), regression pattern of U200 show a dipole structure in the meridional direction. Such dipole structure has positive anomalies in the North and negative anomalies in the south. Moreover, the zero line of the dipole pattern passes through the climatological jet axis, indicating a meridional shift of the jet. Thus, Int and Lat indices are well able to measure the intensification and the meridional displacement of the East Asian jet, respectively.

As suggested in previous studies, both the momentum flux convergence by transient eddies (e.g., Yang et al. 2002; Wettstein and Wallace 2010; Ren et al. 2011; Li and Wettstein 2012) and the angular momentum transport by MOCs (e.g. Li and Wettstein 2012; Martius 2014) can contribute to maintaining the interannual variability of the East Asian jet. Whereas an eddy-driven jet is expected to have an equivalent barotropic vertical structure, exhibiting consistent zonal-wind variations in both tropospheric upper and lower levels, a MOC driven jet is featured by a baroclinic vertical structure with wind responses more confined in the higher troposphere. Based on these thoughts, a simple yet direct analysis is to detect whether there is a consistent variation in zonal wind in the lower troposphere, i.e., regress zonal wind at $850 \mathrm{hPa}$ (U850) against the two jet indices. Regression map of U850 against the Int index shows a positive center of wind anomalies over the central North Pacific and a large negative lobe over the entire Northern North Pacific. Such a pattern is, in general, similar to wind responses at the $200 \mathrm{hPa}$, but the lower tropospheric responses have smaller amplitudes and are more confined over the central and Northeast Pacific (Fig. 3c). Regression map of U850 against the Lat index also shows a zonally-prolonged dipole pattern, which is consistent with the regression map of U200 (Fig. 3d). But again, lower-tropospheric wind responses are weaker and are more confined over the Northeast Pacific. These results suggest that the upstream response of the jet is more baroclinic, whereas the downstream response is more barotropic. Given these qualitative difference in the vertical structure of zonal-wind variability, we wonder if different dominating processes, MOC-driven vs. eddy-driven, control jet variability over up- and down-stream regions, respectively? We will further quantify the region-dependent dynamical control using budget analyses. The two types of variability, intensification and meridional displacement, will be discussed in separate sections.

\subsection{Interannual intensification of the East Asian jet}

In this section, we quantify the contributions of dynamical processes associated with an intensified East Asian jet. The analysis is performed by regressing zonal momentum budget (Eq. 2) to the interannual component of standardized jet intensity index, whose results are shown in Fig. 5 . In the budget congruent with an intensified East Asian jet, the first-order-balance is between the ageostrophic term and the mean-flow advection. The residual of these two terms, which is one magnitude smaller, is further balanced by eddy activities. Our budget analysis indicates distinct processes in driving the up- and down-stream intensification of the East Asian Jet at interannual timescale.

\subsubsection{Upstream acceleration and convective driven local Hadley cells}

Over the upstream of zonal-wind anomalies associated with an intensified East Asian jet, we find two centers of ageostrophic acceleration, which are located over $80^{\circ}-120^{\circ} \mathrm{E}$ and $130^{\circ}-160^{\circ} \mathrm{E}$ (Fig. $4 \mathrm{a}$ ) and span from subtropics to southern mid-latitudes. Such a pattern of ageostrophic acceleration reflects two branches of northward ageostrophic meridional flow in the upper troposphere, further implying that there may be two branches of local meridional circulation over the upstream of an intensified East Asian jet. These cells should be clockwise, i.e., Hadley-cell like, and can transport anomalous upper-level zonal momentum from the tropics to accelerate the jet. Moreover, magnitude of congruent budgets indicate that acceleration associated with local MOC should be the first order contributor.

To test the hypothesis that local Hadley-cell-like overturning circulations accelerate the jet from its upstream, we examine the meridional circulations associated with an intensified East Asian jet. Meridional circulation consists of the meridional (ageostrophic) and the vertical motion, and results are averaged over the Bay of Bengal-South China Sea sector, $80^{\circ}-120^{\circ}$ E (Fig. 5a), as well as the Pacific Warm Pool sector, $130^{\circ}-160^{\circ} \mathrm{E}$ (Fig. $5 \mathrm{~b}$ ). In both sectors, we find local Hadley-like cells that have ascending branches in the tropics, turn northward at the $200-300 \mathrm{hPa}$ level, and extend to subtropics and higher latitudes. The zonal averaged anomalous westerly wind also peaks near the tropopause and locates at $35^{\circ} \mathrm{N}$, indicating that the two local Hadleylike cells transport anomalous tropical upper-tropospheric angular momentum to the latitude and height where the jet intensifies (Fig. 5a, b). Such regression patterns are highly consistent with the feature of a MOC-driven jet. However, over the Bay of Bengal-South China Sea, the ascending branch is at around $10^{\circ} \mathrm{N}$, with descending motion around $40^{\circ}-45^{\circ} \mathrm{N}$. Over the Pacific Warm Pool, ascending motion maximizes at around $5^{\circ} \mathrm{N}$ and descending motion maximizes at around $35^{\circ} \mathrm{N}$. This again indicates that the two cells maybe distinct from one another.

To investigate whether the two local Hadley-like cells are externally driven by heating from tropical convective activities, we also apply regression analyses to outgoing 
(a) Ageostrophic

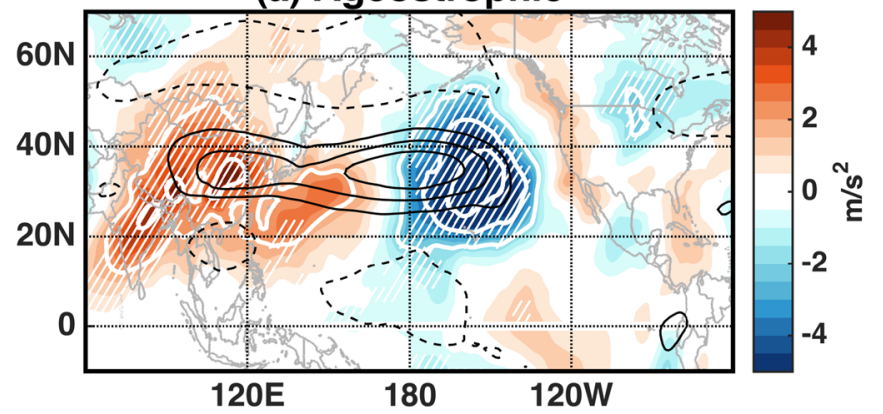

(b) Mean-flow advection
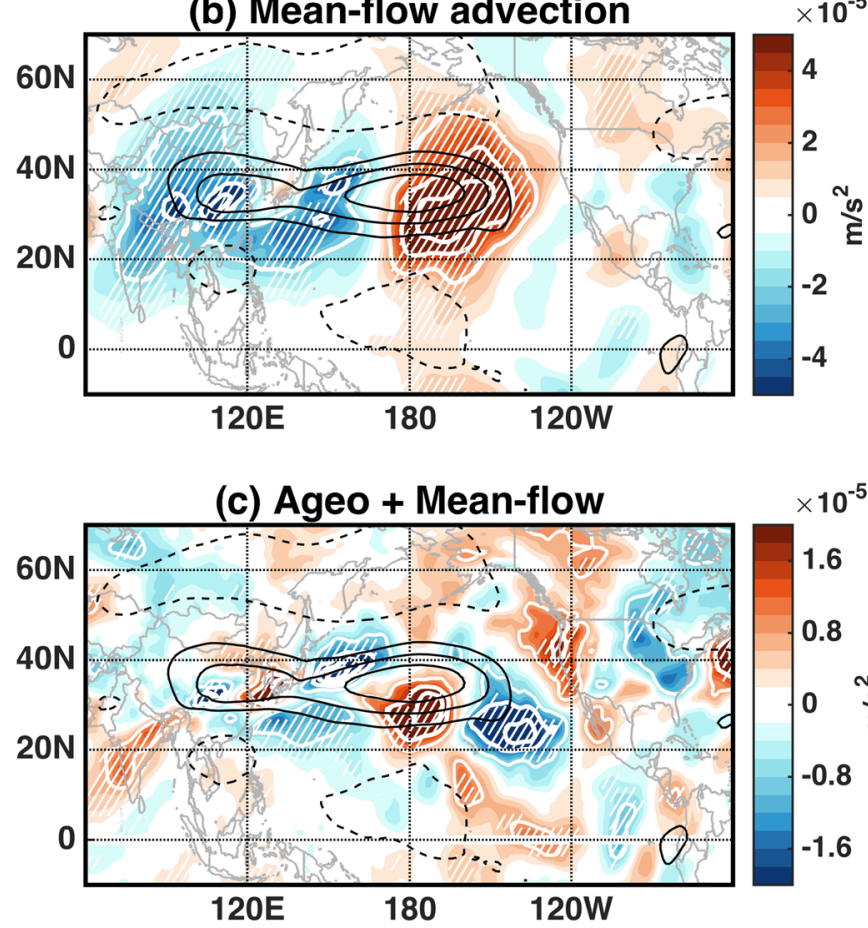

(d) High-frequency eddies

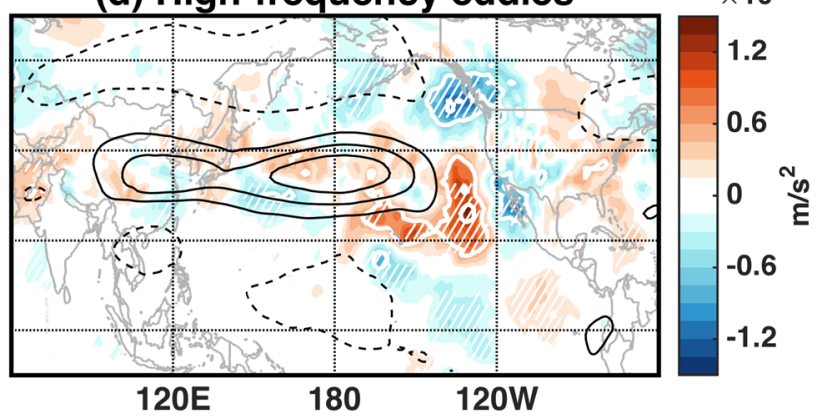

(e) Low-frequency eddies
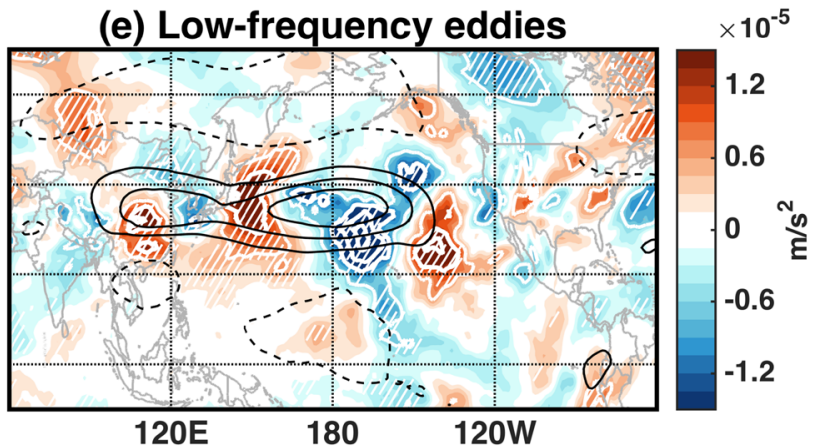

(c) Ageo + Mean-flow

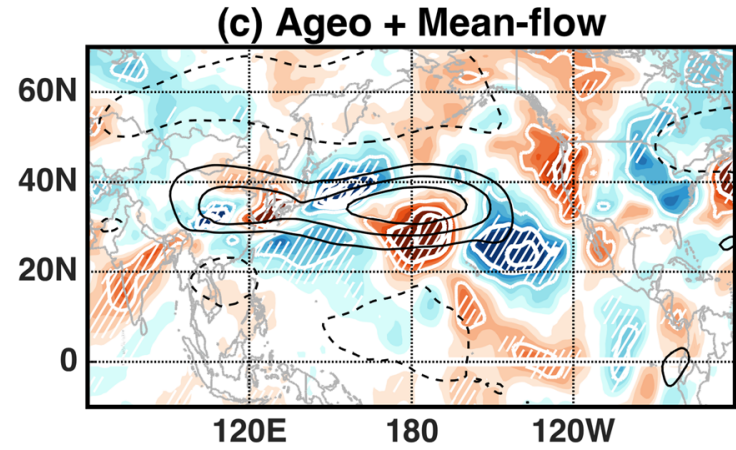

Fig. 4 Zonal momentum budgets (Eq. 2) associated with an intensified East Asian jet. Shown maps are the regression patterns for a ageostrophic acceleration, $\mathbf{b}$ mean-flow advection, $\mathbf{c}$ summation of terms in $\mathbf{a}, \mathbf{b}$ and $\mathbf{d}$ synoptic eddy-momentum-flux convergence, e low-frequency eddy-momentum-flux convergence, and $\mathbf{f}$ summation of terms in $\mathbf{d}$ and $\mathbf{e}$. The first-order balance is between the ageostrophic accel- eration and the mean-flow advection, and their residuals are balanced on the second order by eddy activities. Note that color scales are different for individual panels. Contour lines are the $200 \mathrm{hPa}$ zonal-wind responses as in Fig. 3a. White shadings denote significance at the $90 \%$ level

meridional circulation is located. For the Pacific Warm Pool sector, the center of anomalous rain band is at around $5^{\circ} \mathrm{N}$, which is also consistent with the location of the ascending branch in the west Pacific. Consistent with results found in precipitation, significant decrease in OLR, which indicates an increase of cloud-top emission height (Kiehl and Trenberth 1997) and thus more active convections, is found in corresponding regions over both the Bay of Bengal-South China Sea and the Pacific Warm Pool (Fig. 6a). Similarly, positive CAPE anomalies are found collocated with OLR and precipitation signals (Fig. 6c). Convective-driven local Hadley Cells, therefore, play the dominating role in the 
Fig. 5 Local meridional overturning circulations associated with an intensified East Asian jet. Shown patterns are the regression maps for a meridional circulation $\left(v_{a}\right.$ and $\left.w\right)$ averaged over $80^{\circ}-120^{\circ} \mathrm{E}$, b over $130^{\circ}-160^{\circ} \mathrm{E}$, and $\mathbf{c}$ over $180^{\circ}-140^{\circ} \mathrm{W}$. Filled contours are the zonal-wind responses vectors indicate significance at the $90 \%$ level. Red horizontal vectors denote $1 \mathrm{~ms}^{-1}$ for $v_{a}$ and the vertical red vector denotes $5 \times 10^{-3} \mathrm{Pas}^{-1}$ for $w$ averaged over 80-160 E. Black

(a) 80-120E Mean

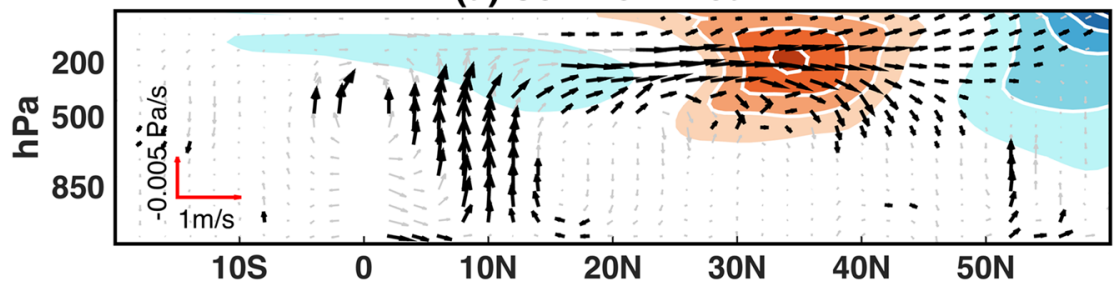

(b) 130-160E Mean

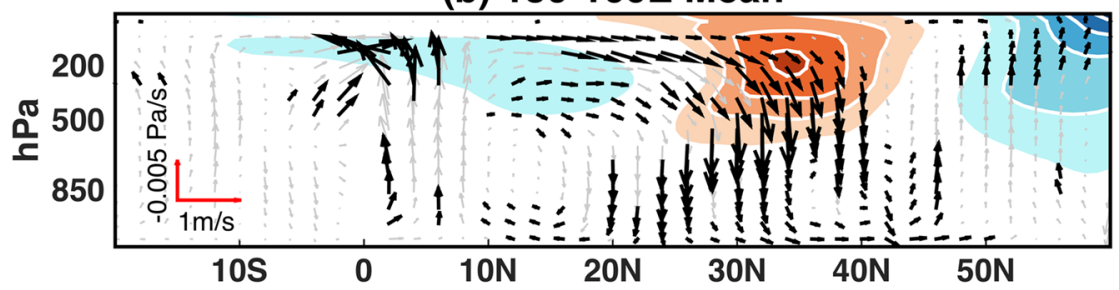

(c) 180-140W Mean

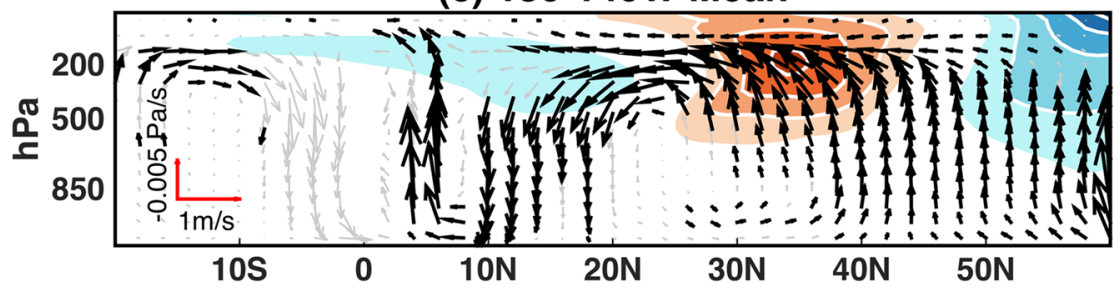

Fig. 6 Tropical convective
activities associated with an intensified East Asian jet. Shown patterns are the regression maps for a outgoing longwave radiation, $\mathbf{b}$ precipitation, and $\mathbf{c}$ convective available potential energy. All fields are from the ERA-interim reanalysis and white shadings denote significance at the $90 \%$ level (a) OLR

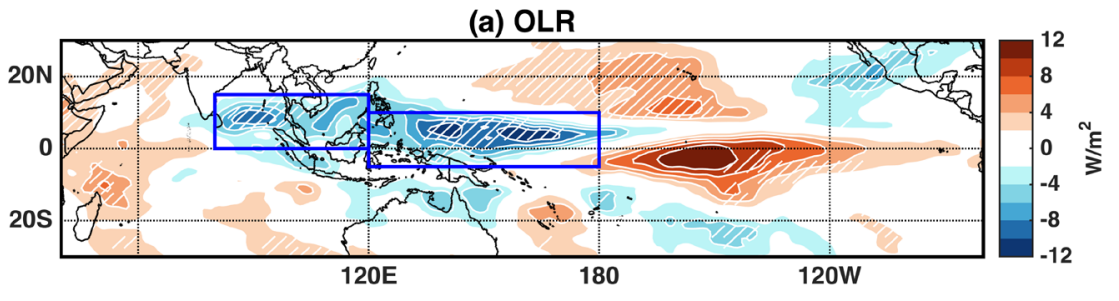

(b) $\mathrm{Pr}$

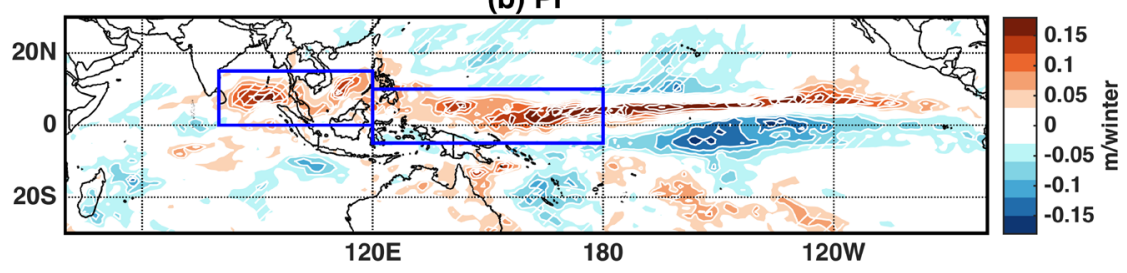

(c) CAPE

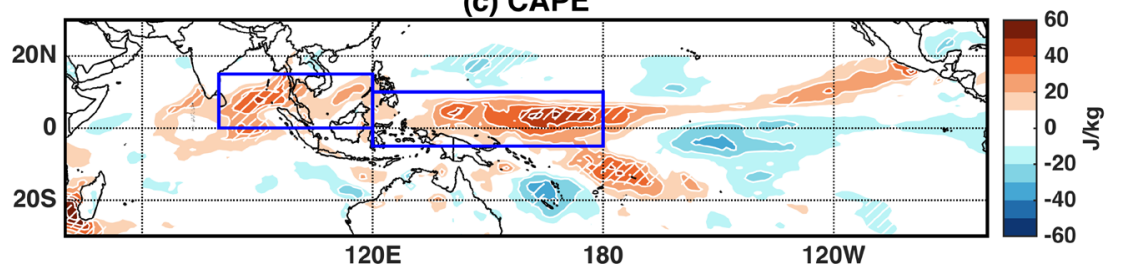

interannual intensification of the wintertime East Asian jet over the upstream region. Moreover, in addition to the previously suggested western tropical Pacific, anomalous convective heating over the Bay of Bengal-South China Sea also have a significant contribution.

\subsubsection{Downstream acceleration, eddy activities, and Pacific Subtropical oceanfront}

Anomalous upper-level zonal momentum injected by two convective driven local Hadley Cells is advected to the 
downstream by the mean flow (Fig. 4b), resulting in a pattern that decelerates the jet over the upstream and accelerates over the downstream. The effect of mean-flow advection is opposite to that of the ageostrophic term. As a result, over the downstream region, though mean-flow accelerates the jet by advecting excessive zonal momentum to the northeast Pacific, the ageostrophic term decelerates the jet. Deceleration associated with ageostrophic flows reflects southward ageostrophic meridional-wind in the upper troposphere, which indicates the existence of a local Ferrell-like cell in the downstream region (Fig. 5c).

Contributions of eddy activities are quantified by regressing the convergence of eddy momentum fluxes. Though eddies tend to play a secondary role compared with the mean-flow advection, synoptic eddies show convergence of momentum fluxes over regions extending from central North Pacific to North America between $30^{\circ}$ and $40^{\circ} \mathrm{N}$ (Fig. 4d), which helps to accelerate and maintain intensified westerlies over the downstream region. There is also divergence of synoptic eddy momentum fluxes outside $30^{\circ}-40^{\circ} \mathrm{N}$, indicating that synoptic eddies also decelerate westerlies outside the subtropics and contribute to the sharpening of the jet.

Influences of synoptic eddies can also be quantified with E-vector, $\mathbf{E}=\left(\overline{v_{h}^{2}-u_{h}^{2}}, \overline{-u_{h} v_{h}}, f_{0} \overline{v_{h} \theta_{h}} / \Theta_{p}\right)$, and its divergence (Hoskins et al. 1983). $\Theta_{p}$ is the static stability parameter in pressure coordinate and defined as the vertical derivative of mean potential temperature. Because the vertical component of a 3D E-vector is always weaker in the upper troposphere, we only examine its horizontal components, namely $\mathbf{E}=\left(\overline{v_{h}^{2}-u_{h}^{2}}, \overline{-u_{h} v_{h}}\right)$, where $u_{h}$ and $v_{h}$ are the synoptic components of zonal and meridional wind speed at the $200 \mathrm{hPa}$ level. The x-component of E-vector can reflect shapes of waves, and the y-component takes the negative sign of meridional eddy momentum flux. The E-vector approximates the group velocity of waves relative to a mean flow and $\mathbf{- E}$ can be considered as an effective westerly momentum flux (Hoskins et al. 1983). A diverging E-vector is associated with a local acceleration of the timemean westerly flow, and vice versa (Hoskins et al. 1983). The regression map of E-vector and its divergence suggests the contribution of synoptic eddies in enhancing and sharpening the jet over the downstream region (Fig. 7). The anomalous westerly and easterly E-vector passes through the positive and negative centers of U200 regressions, respectively, and the associated divergence favors a reinforcement of the anomalies U200 field. Interestingly, a similar pattern in E-vector and its divergence is found during westward shifts of the East Asian trough, which, however, is associated with a deceleration of jet over central North Pacific (Leung and Zhou 2015). Compared with synoptic eddies, low-frequency eddies have stronger responses (Fig. 4d). However, their regression map shows a wave-train-like pattern that passes through the intensified jet and the net effect with respect to accelerating the jet is not evident.

Similar to tropical convections associated with the upstream acceleration, we also look for external signals associated with jet variability over the downstream region. We find that intensification of the upper tropospheric East Asian jet is closely coupled to boundary sea surface temperature (SST) conditions at the interannual timescale. Such covariation is quantified by regressing DJF-mean SST fields upon the normalized Int index, which is shown in Fig. 8. Regression pattern of SST is characterized by negative SST anomalies over the northwest and central North Pacific, together with positive SST anomalies over the equatorial central and eastern Pacific. Such a pattern in Fig. 8a

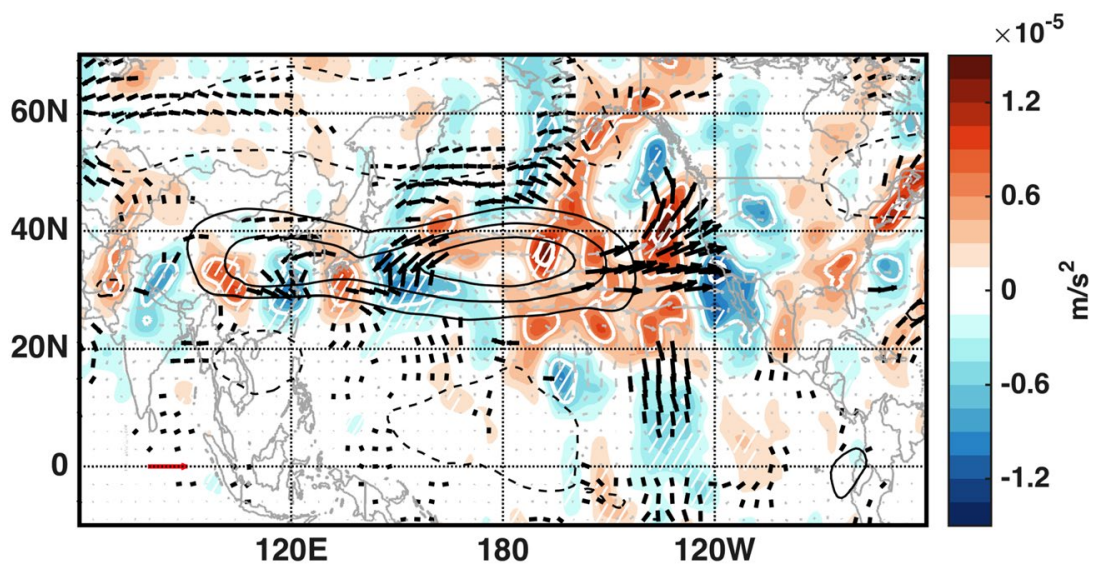

Fig. 7 E-vectors associated with an intensified East Asian jet. Synoptic eddies maintain the strengthening of the East Asian jet over the downstream region. Shown diagnoses are regression maps of the twodimensional synoptic E-vectors (vectors) and their divergence (color shadings) at the $200 \mathrm{hPa}$ level. Variations less than 10-days are fil- tered from the 6-h data to compute the synoptic E-vectors. Contour lines are the $200 \mathrm{hPa}$ zonal-wind responses as in Fig. 3a. Black vectors and white shadings denote significance at the $90 \%$ level. The red vector represents $20 \mathrm{~m}^{2} \mathrm{~s}^{-2}$ 
(a) SST - DJF

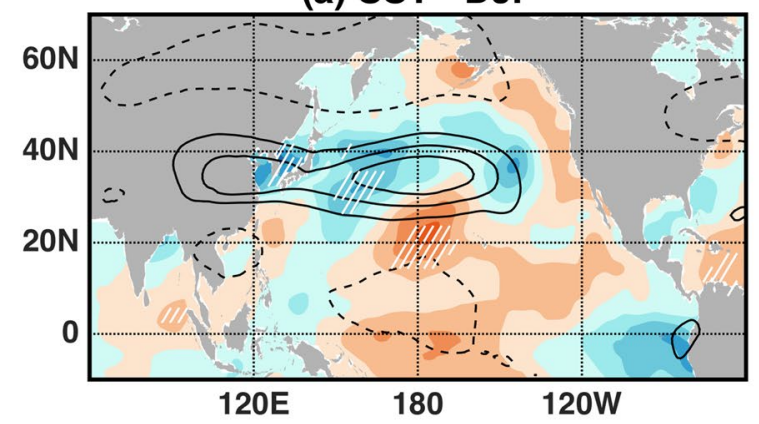

(c) SST - SON

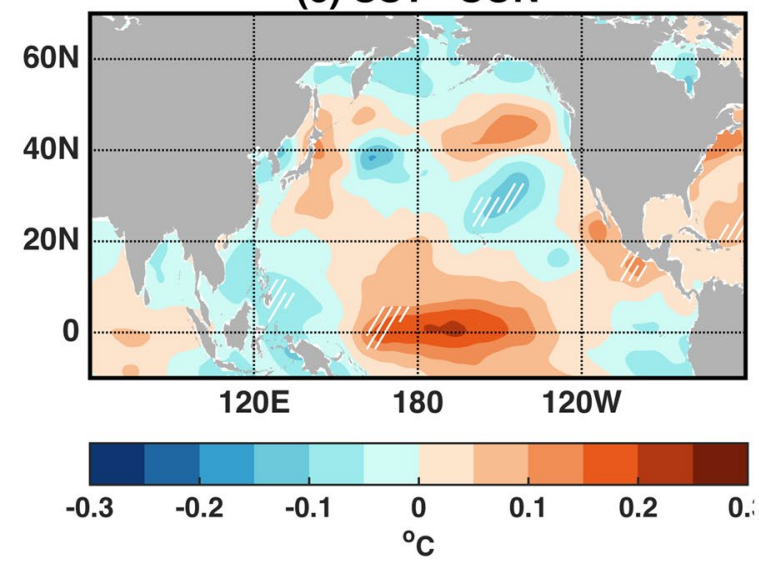

(b) SST grd DJF

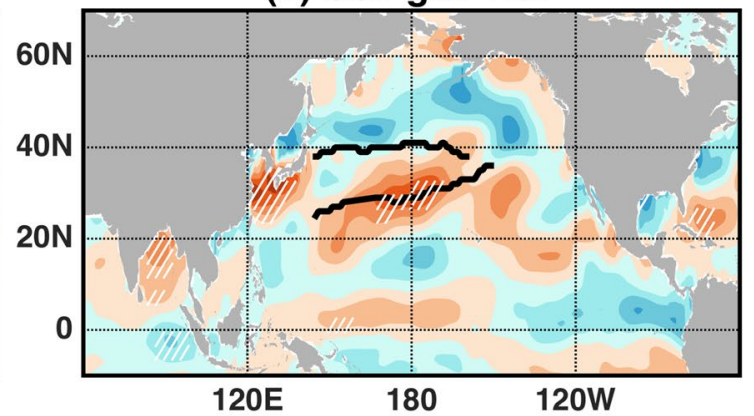

(d) SST grd - SON

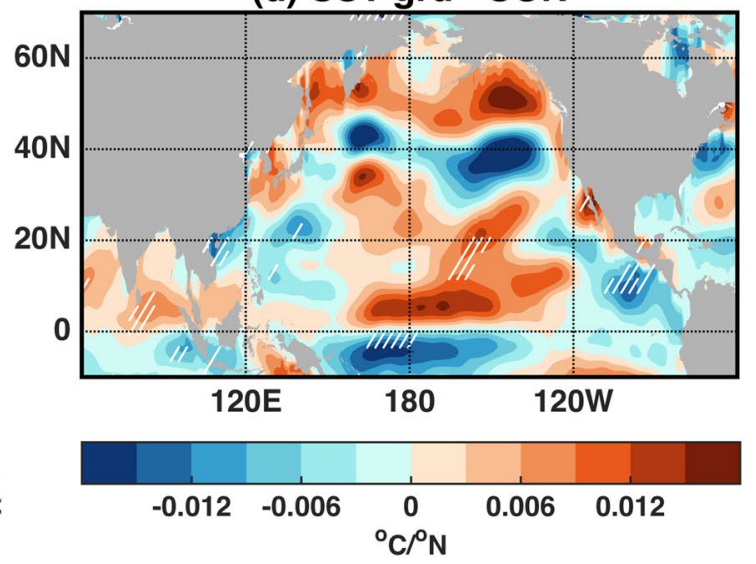

Fig. 8 Sea surface temperature (SST) associated with an intensified East Asian jet. The intensified East Asian jet is coupled with an intensified Pacific Subtropical oceanfront. Shown maps are the regression patterns for a DJF SST (color shading), and b DJF meridional SST gradient. Contour lines in a are the DJF $200 \mathrm{hPa}$ zonal-wind responses

resembles the positive phase of the Pacific Decadal Oscillation (Mantua et al. 1997). In the extratropics, the dipole pattern of SST anomalies can be driven by stronger surface wind through Ekman-layer processes or changes in surface latent heat fluxes (Yang et al. 2002). Such a change in SST tend to increase the meridional SST gradient, i.e., boundary baroclinicity. There are two oceanfronts over the Northwest and central North Pacific, defined by sharp meridional SST gradient. The extra-tropical front, located at $40^{\circ} \mathrm{N}$, is suggested to be driven by the convergence of Kuroshio and Oyashio; and the subtropical front, located at $28^{\circ} \mathrm{N}$, is proposed to be atmospheric driven (Wang et al. 2017). Interestingly, increased SST gradient associated with an intensified jet is over $28^{\circ} \mathrm{N}$ and from $140^{\circ}$ to $220^{\circ} \mathrm{E}$, which is the climatological position of the Pacific Subtropical oceanfront. This result shows that during winter, the Pacific Subtropical oceanfront is stronger when the East Asian jet is intensified. The stronger oceanfront may feedback and help to maintain the downstream intensification of the upper-tropospheric jet through eddy activities and thermal wind balance, as as in Fig. 3a, and thick black lines in $\mathbf{b}$ are the wintertime climatological positions of the Pacific Subtropical oceanfront and the Pacific Sub-polar oceanfront. White shadings denote significance at the $90 \%$ level. Bottom panels are similar to top panels but are regression maps of SST and its gradient in the preceding fall (SON)

suggested by a recent regional model study (Huang et al. 2020). In addition, significant but weaker SST anomalies are also found in tropical Indian Ocean and equatorial central Pacific, in general similar to that with the variability of East Asian winter monsoon in Wang and Chen (2014), suggesting the connection between the variations of the two (Wang and Lu 2017; Chowdary et al. 2019).

We also investigated SST anomalies in the preceding fall using regression analysis, but do not find significant signals over the North Pacific (Fig. 8c, d), implying that the coupling between a strengthened upper-tropospheric jet and intensified boundary baroclinicity are likely simultaneous. This result also indicates that extratropical SSTs do not provide apparent seasonal predictability. However, an intensified East Asian jet is associated with positive SST anomalies over the equatorial central Pacific in the fall before an intensification of the East Asian jet occurs (Fig. 8c). Increased equatorial central Pacific SST can excite the Pacific-North-American pattern (Wallace and Gutzler 1981) and then maintain an intensified jet through synoptic 
eddy feedbacks, as suggested by many previous studies (e.g. Wettstein and Wallace 2010; Franzke et al. 2011; Li and Wettstein 2012), though it is not yet clear why there is a seasonal lag in between, and why the tropical signal is not as clear in the regression of wintertime SST.

To briefly summarize the distinct up- and downstream controls for the intensification of the East Asian jet, the upstream shows more characteristics of a MOC-driven subtropical jet, whereas the downstream shows more characteristics of an eddy-driven jet. Two convective driven local Hadley Cells, which originates in the equatorial Western Pacific and the Bay of Bengal-South China Sea, transport upper-level zonal momentums over the upstream region and play a predominant role in accelerating the jet. This additional zonal momentum is advected to the downstream and elongates the zonal wind anomalies by the mean-flow. In addition to the mean-flow advection, synoptic eddies, though on the second order, accelerate and reinforce the intensified and sharpened jet over the downstream region. The downstream variability of a strengthened East Asian jet is found to covary with that of the Subtropical oceanic front in the North Pacific. The wintertime jet intensification also seems to be associated with positive SST anomalies over the equatorial central Pacific in the preceding fall.

\subsection{Interannual meridional displacement of the East Asian jet}

In this section, we will investigate processes responsible for the poleward shift of the East Asian jet. We start by projecting zonal momentum budgets against the Lat index (Fig. 9). Similar to the intensification of the jet, the first-order balance in zonal momentum budget associated with the poleward shift of the East Asian jet is still between the ageostrophic term and the advection of the mean-flow (Fig. 9a, b). Two centers of ageostrophic acceleration are found over East Asia and the tropical-subtropical eastern Pacific, whereas a northeast-southwest oriented lobe of ageostrophic deceleration is found over the central North Pacific. Such a pattern is, in general, not consistent with that of U200 variation. The residual of the two terms is, again, one magnitude smaller and is balanced by eddy activities. For synoptic eddies, we find their anomalous momentum flux convergence is generally consistent with the meridional shift of the jet. Convergence of momentum fluxes associated synoptic eddies show a nearly zonally-prolong dipole pattern, with accelerations over the Northern North Pacific (Fig. 9c). More definite evidence of synoptic eddy contributions comes from analyzing E-vector and its divergence. As shown in Fig. 10, the regression pattern of E-vector shows two zonally-prolonged flows of wave energy and are concentrated over the eastern North Pacific. Whereas the one flow over $40^{\circ}-60^{\circ} \mathrm{N}$ is westward, the one over $20^{\circ}-30^{\circ} \mathrm{N}$ is eastward and turns to the Equator at around $150^{\circ} \mathrm{W}$. Moreover, the divergence of anomalous E-vector shows a meridionally distributed dipole structure, with E-divergence found over the northern North Pacific and convergence over the eastern North Pacific (Fig. 10). These results suggest the dominating role of synoptic eddy activities in reinforcing meridional displacements of the East Asian jet. On the other hand, low-frequency eddies show a wave-train-like response, but, similar to the case of jet intensification, the overall pattern of low-frequency eddies is not consistent with U200 responses (Fig. 9d).

\subsubsection{Eddy activities and related extra-tropical process}

Our budget analysis reveals the important role of synoptic eddy activities in maintaining the meridional displacement of the jet. We therefore further investigate whether such changes of synoptic eddies are supported by changes in surface baroclinicity, which is similar to the case of jet intensification. To test the covariance between boundary baroclinicity and the meridional displacement of the East Asian jet, we regress SST fields against the normalized Lat index and find significant signals over the North Pacific. The regression pattern of SST shows a dipole structure over the North Pacific, with positive SST anomalies in the south (Fig. 11a). The changes of SST are similar to SST anomalies associated with a positive phase of the North Pacific Gyre Oscillation (Lorenzo et al. 2008). Moreover, the associated meridional gradient of SST increases over $30^{\circ}-40^{\circ} \mathrm{N}$ and decreases over $20^{\circ}-30^{\circ} \mathrm{N}$ (Fig. 11b). Compared to the climatological position of the oceanic fronts in the wintertime North Pacific, such changes in meridional gradient of SST represent a poleward shift of the Subtropical oceanic front. The diagnosed covariation between the meridional displacements of the upper tropospheric East Asian jet and the surface Subtropical oceanic front suggests a possible sea-air coupling via the anomalous surface fluxes and atmospheric eddy activities (Zhang and Stone 2011; Xiao et al. 2016), which can help maintain and reinforce the latitudinal shift of the jet.

In addition to wintertime SST, significant SST anomalies are also found existing in the preceding fall. As shown in Fig. 11c, the warm SST anomalies in western North Pacific and cold SST anomalies in the north around the Bering Strait already exist in the preceding months in the year that the winter jet locates more poleward. The meridional SST gradient in Fig. 11d exhibits consistent variation in the midlatitude North Pacific. The results suggest that the variability of SST and oceanic front in the North Pacific not only helps maintain the latitudinal shift of the East Asian jet but also provides possible source of predictability of the latitudinal position of the jet stream. 
(a) Ageostrophic

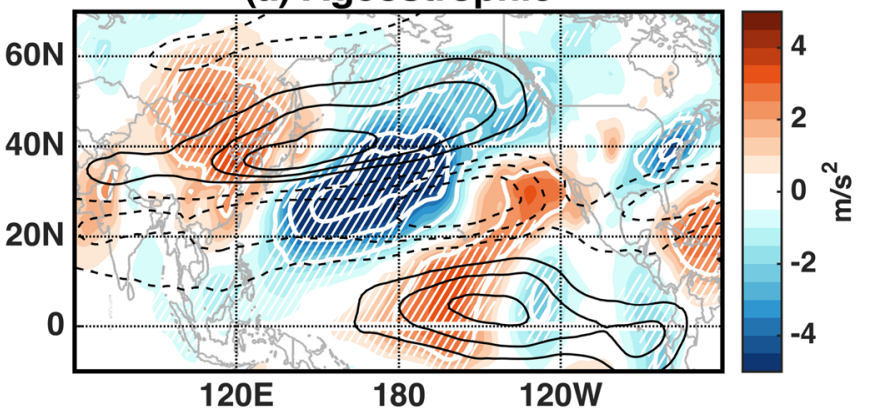

(b) Mean-flow advection

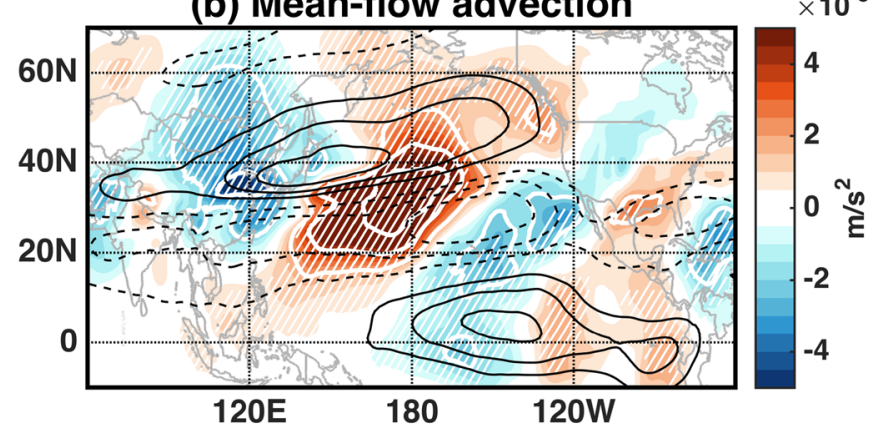

(c) Ageo + Mean-flow

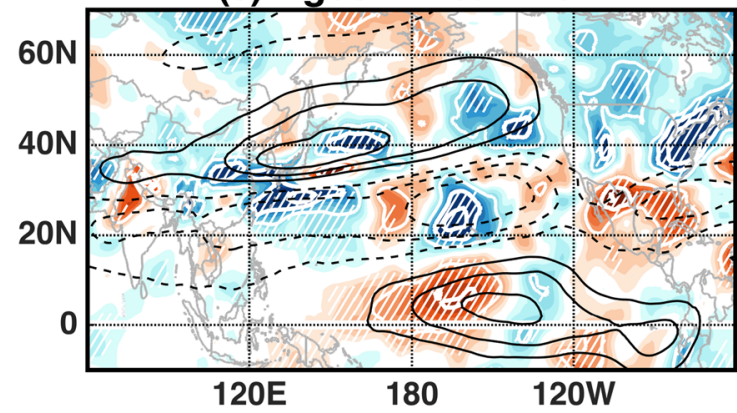

(d) High-frequency eddies
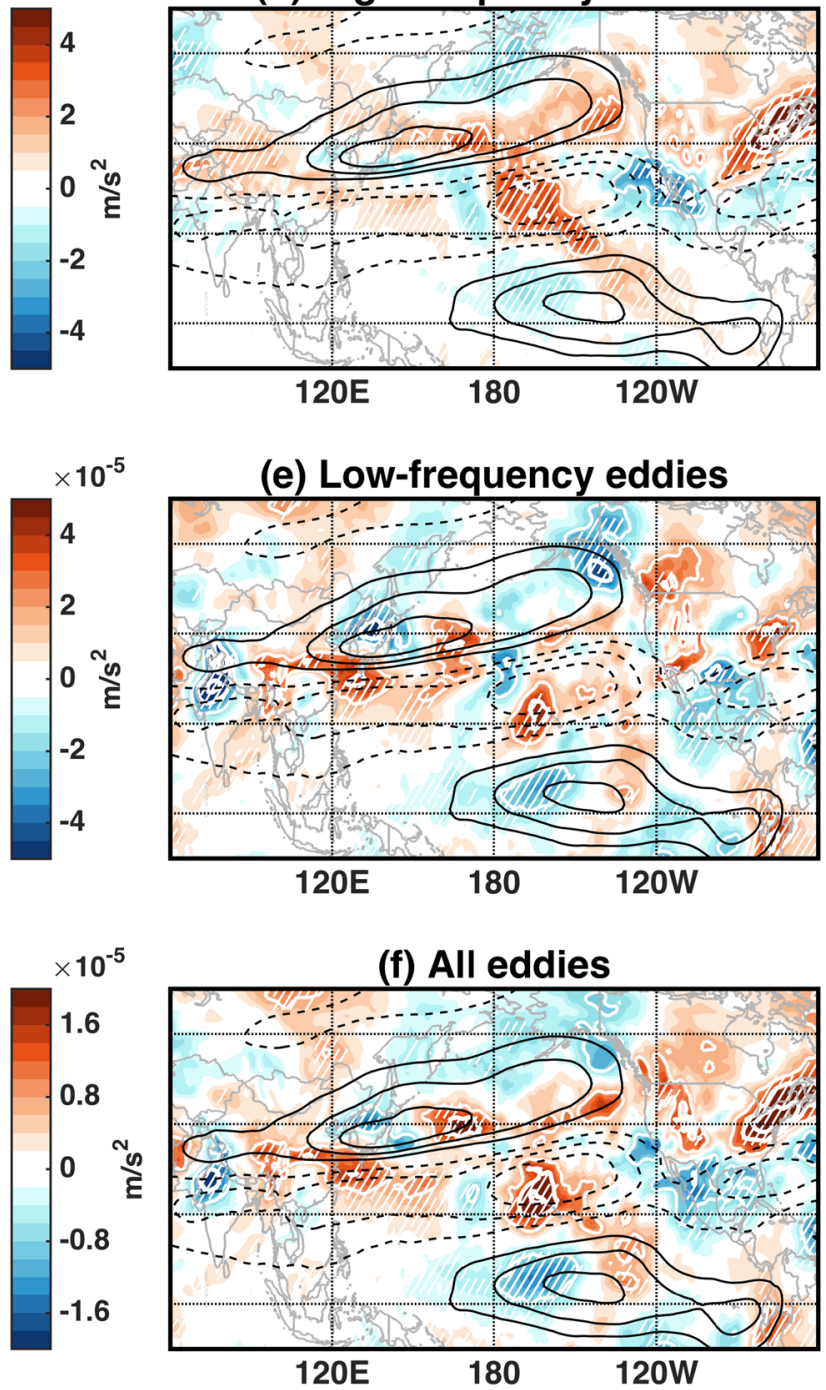

(e) Low-frequency eddies

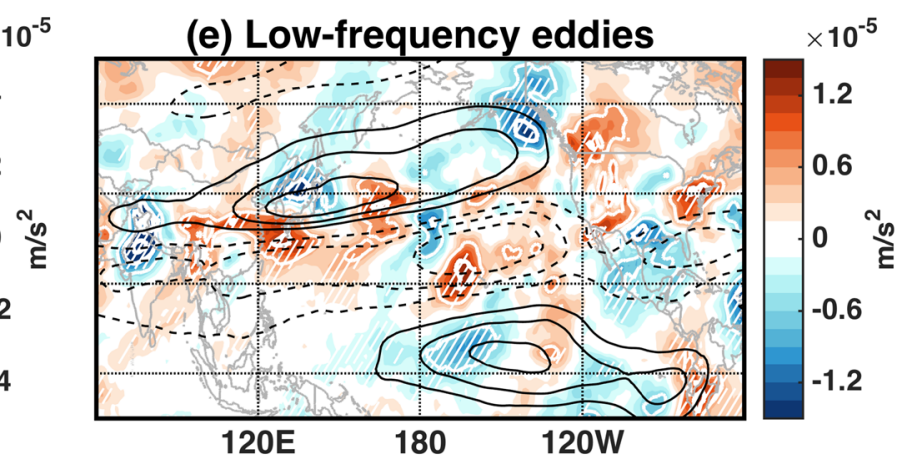

(f) All eddies

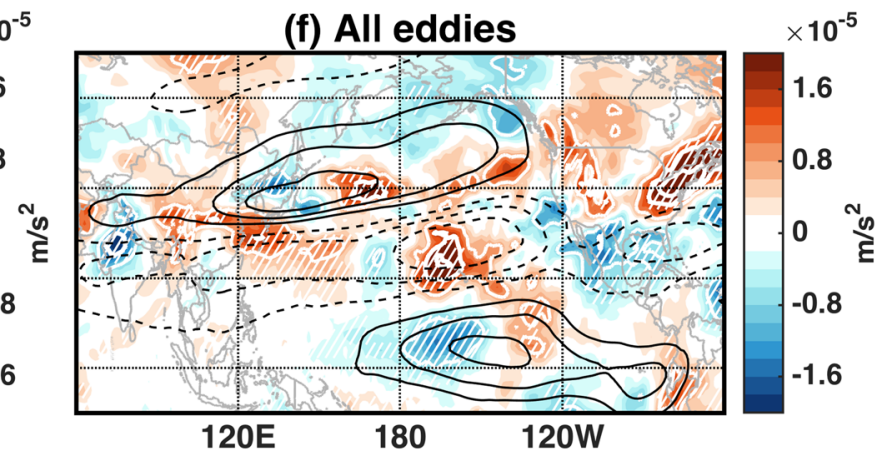

$\times 10^{-5}$

1.2

0.6

$0 \stackrel{\text { Non }}{\xi}$

$-0.6$

$-1.2$

Fig. 9 Zonal momentum budgets (Eq. 2) associated with a poleward shift of the East Asian jet. The layout of the figure is the same as that in Fig. 4, but regressions are computed against the normalized Lat index

Fig. 10 E-vectors associated with a poleward shift of the East Asian jet. The layout of the figure is the same as that in Fig. 7, but regressions are computed against the normalized Lat index

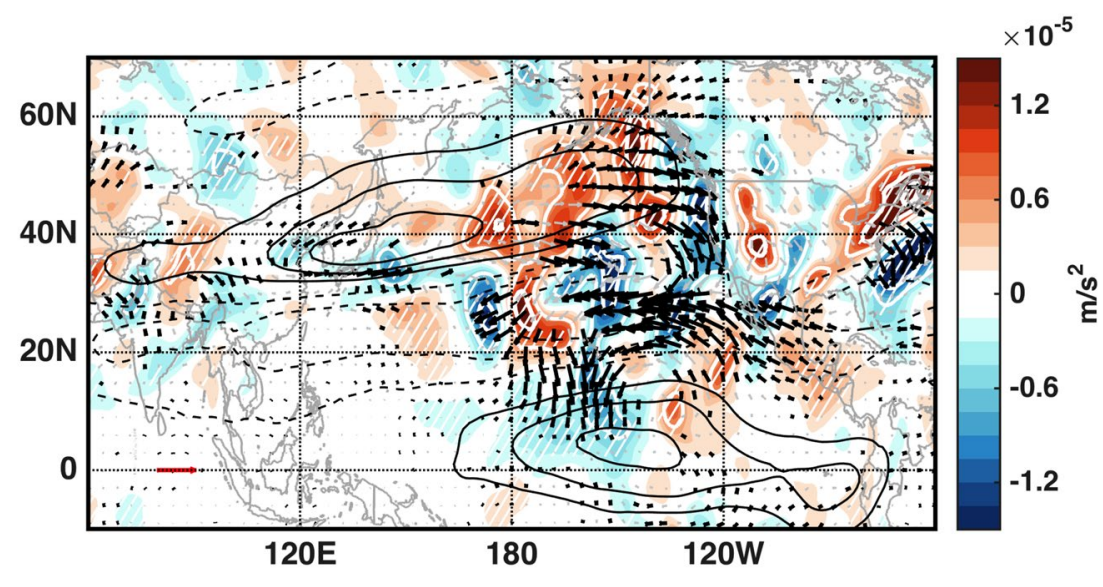


(a) SST - DJF

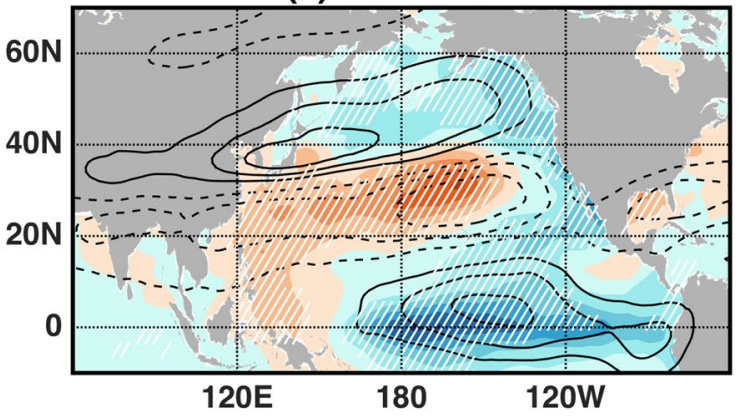

(c) SST - SON

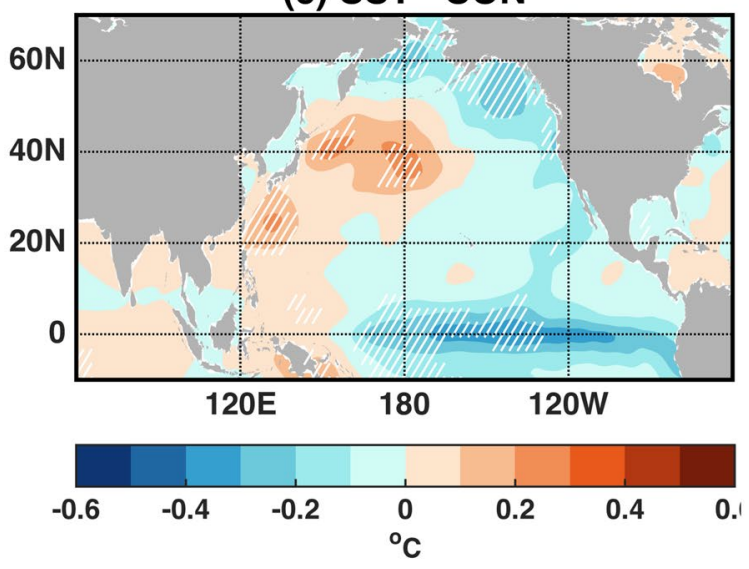

(b) SST grd DJF

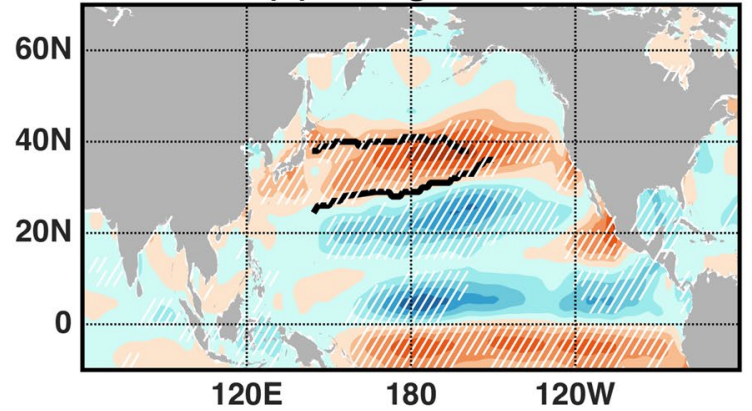

(d) SST grd - SON

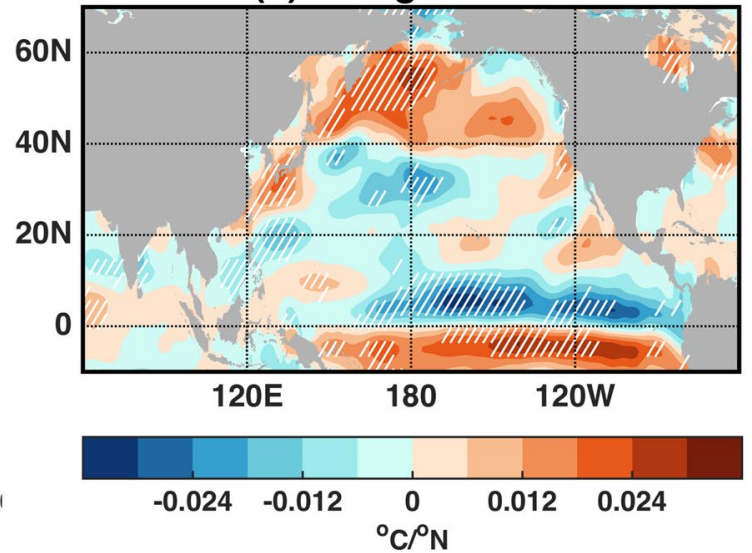

Fig. 11 SST associated with a poleward shift of the East Asian jet, which shows a covarying poleward displacement of the Pacific subtropical oceanfront. The layout of the figure is the same as that in Fig. 8, but regressions are computed against the Lat index

\subsubsection{On the possible role of tropical process}

In addition to SST signals in extra-tropics, significant SST signals also emerge in the tropics in Fig. 11a, with negative SST anomalies over the equatorial central and eastern Pacific and positive SST anomalies over the equatorial western Pacific. Such La Niña-like SST anomalies are also detected in the preceding fall. As shown in Fig. 11c, we find weaker but consistent SST signals that are negative over the equatorial central and eastern Pacific and positive over the equatorial western Pacific. The overall pattern of tropical SST in the preceding fall resembles the feature of a developing La Niña event, which remains and develops to be stronger in the following winter.

Although the tropical processes are not found directly contributing to the jet shift in the zonal momentum budget analysis, there are significant tropical SST anomalies existing in the winter and in the preceding fall, which suggests potential source for seasonal prediction of jet variabilities. Thus, it is worth further investigating the role of tropical processes in the jet shift. More analyses are performed by investigating signals in meridional circulation and convective proxies. Since the convective proxies such as
OLR, precipitation and CAPE exhibit consistent results, here we only present results for OLR. The pattern of tropical convective anomalies agrees well with that of SSTs. As shown in Fig. 12b, negative OLR anomalies (positive convective latent heat release) are found over equatorial western Pacific, whereas a positive center of OLR anomaly (negative convective latent heat release) is found over the central tropical Pacific. The positive SST anomalies over the equatorial Western Pacific collocate with more active regional convections. The corresponding change in local meridional overturning circulation (averaging over $80^{\circ}$ $-140^{\circ} \mathrm{E}$ ) is also investigated in Fig. 12a, which shows an upward motion rising from $10^{\circ}$ to $20^{\circ} \mathrm{N}$, consistent with the convective anomalies. However, the associated upward motion mainly turns southward in the upper troposphere. Compared with the climatological distribution of meridional circulations over the region (as shown in the scheme in Fig. 1b), such anomalies suggest a weakened local Hadley cell, which decreases the cross-equatorial transport of upper-level angular momentum from the Southern Hemisphere. In such situation, the tropical control of the East Asian jet is weaker. Eddy activities and extra-tropical processes may play a more important role. 
Fig. 12 Tropical convective activities associated with a poleward shift of the East Asian jet. No significant closed meridional circulation associated with the jet shift is found. Shown patterns are the regressions for a meridional circulation $\left(v_{a}\right.$ and $w$ ) averaged over $80^{\circ}-140^{\circ}$ $\mathrm{E}$, and $\mathbf{b}$ outgoing long-wave radiation. Layouts of individual panels are the same as those in Figs. 5 and 6 (a) $80-140 E$ Mean

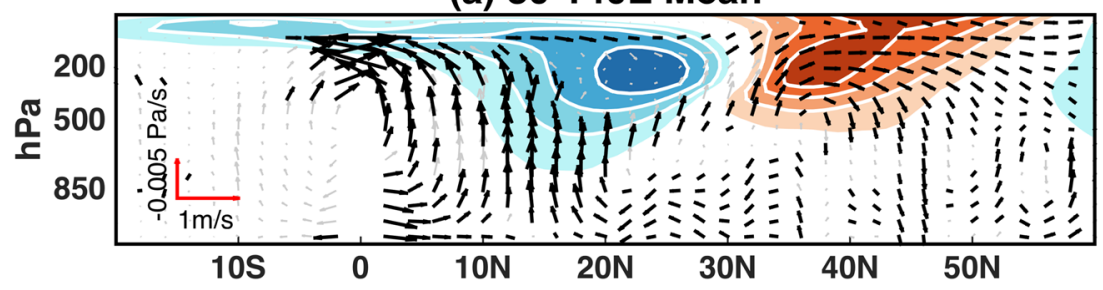

(b) OLR

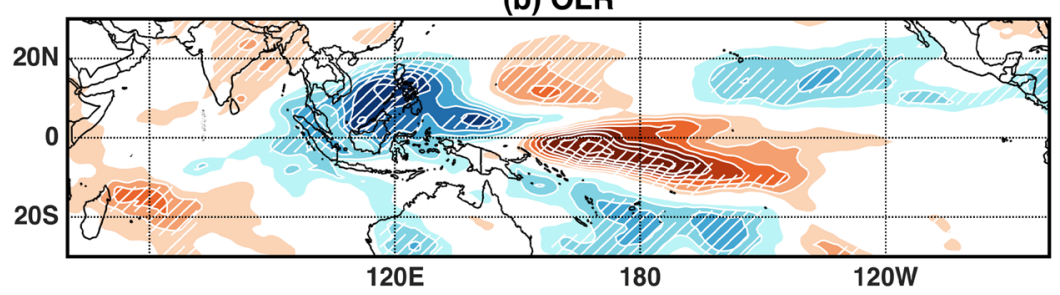

\section{Discussions and conclusions}

In this study, we diagnosed the zonal momentum budget associated with the interannual intensification and meridional shift of the East Asian jet, and quantified relative contributions of distinct dynamical processes that have been proposed to be responsible for these interannual variabilities. Figure 13 summarizes the dominating dynamical processes.

Intensification of the East Asian jet (Fig. 13a), though has been suggested to be both thermal driven ( $\mathrm{Li}$ and Wettstein 2012) and eddy-driven (Yang et al. 2002; Wettstein and Wallace 2010), is illustrated by our analyses

(a) Strengthening of East Asian Jet

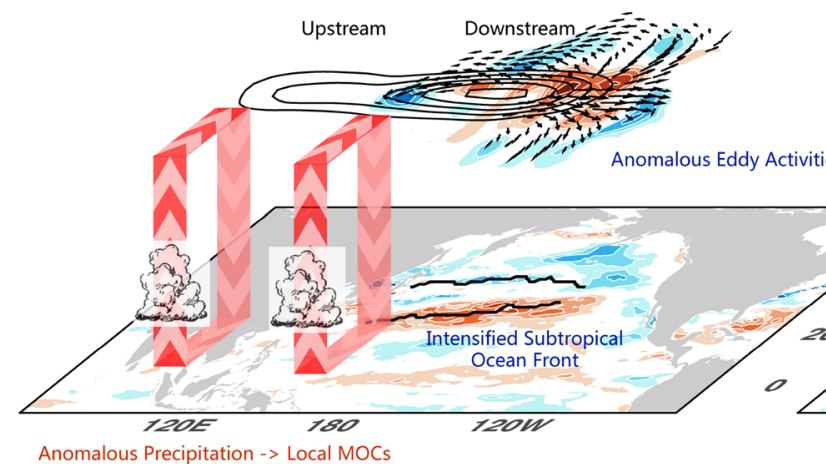

Anomalous Precipitation -> Local MOCs

Fig. 13 Summary schematics of processes responsible for wintertime interannual variabilities of the East Asian jet. a An intensification of the jet is triggered by convections over the 'Bay of Bengal (BOB)South China Sea (SCS) and Pacific Warm Pool over the upstream and maintained by feedback with Pacific Subtropical oceanfront through eddies over the downstream. b A poleward shift of the jet is mainly driven by eddies and is also coupled to the North Pacific subtropical oceanic front. Black contours denote zonal-wind anomalies at the to be controlled by different processes over the up- and down-stream of the jet. For the upstream, enhanced upperlevel angular momentum transported by convective driven local Hadley cells plays the predominant role and very likely triggers the jet intensification. In addition to the convective heating over the equatorial Western Pacific as studied in Yang et al. (2002) and Li and Wettstein (2012), excessive convective heating over the Bay of Bengal-South China Sea also contributes, together corresponding to the two branches of thermally direct meridional circulations that are diagnosed over the upstream region (red circulations in Fig. 13a). Thus, the convective heating over the Bay of Bengal-South China Sea, in addition to the climatology of the East Asian jet (Martius 2014), is also crucial 
for the interannual variability of the jet strength. Our finding shows that, in addition to the tropical heating induced Rossby wave train as suggested in Zheng et al. (2013) and Yang et al. (2010), heating over the Bay of Bengal to the equatorial Western Pacific can affect the winter climate of East Asia more directly through a thermally driven local Hadley Cell. Such upstream control of tropical convective heating on the jet intensity is also supported by a previous model study (i.e., He et al. 2011), in which the East Asian jet is shown intensified from $100^{\circ} \mathrm{E}$ to the downstream when heating is added over the Maritime continent and intensified in the upstream $70^{\circ}-100^{\circ} \mathrm{E}$ when heating is added over the Bay of Bengal and Indian Ocean. In addition to existing model studies, potential appears in future works to replicate and further understand the series of dynamical processes leading to the variabilities of East Asian jet in coupled or sophisticated models. For the downstream, intensification of the East Asian jet is, on the first order, maintained by the mean-flow advection of angular momentum from the upstream. Synoptic eddies contribute, on a second order, to maintain, sharpen, and anchor the intensified jet by converging eddy momentum laterally. The subtropical oceanic front in the North Pacific, which has been raised more attentions recently (Fang and Yang 2016; Wang et al. 2017), shows highly consistent variation with the jet intensification, suggesting that the air-sea coupling via the interactions between Ekman transport, surface flux and atmospheric eddy feedbacks may also play a role in the downstream intensification of the East Asian jet.

Our budget analyses further show that poleward shift of the East Asian jet is greatly driven by synoptic eddy activities. In such situation, the local Hadley cell is weaker and no consistent tropical processes are found directly contributing to the jet shift. As summarized in Fig. 13b, the subtropical oceanic front in the North Pacific is also found to covary with the meridional displacement of the jet. Such strong and significant SST anomalies are found already existing in preceding months, providing potentials for seasonal predictions of the jet position. We noticed that some recent studies suggest the connection between the East Asia jet stream and the East Asian winter monsoon via associated stationary wave trains (Liu et al. 2014; Chowdary et al. 2019). We also tested this hypothesis by analyzing wave activity fluxes proposed by Takaya and Nakamura (2001) and do not find a conclusive contribution of stationary wave trains propagating from the upstream (not shown). Whether the latitudinal displacement of the jet is driven by other external forcing, e.g. Arctic forcing as shown in Overland et al. (2015), Gu et al. (2018) and Zhang et al. (2019), or it is mostly determined by atmospheric internal dynamics is a topic that needs further investigation.
In addition to the intensification and the meridional shift, the elongation of the East Asian jet is reported another mode of jet variability, which is featured by positive zonal-wind anomalies over the northeast Pacific (Athanasiadis et al. 2011; Li and Wettstein 2012). As the zonal wind variation associated with an elongated jet is confined over the northeast Pacific and has no significant projections over the climatological jet core region, such variability cannot be effectively captured by the jet indices we defined. Therefore, though our jet core index exhibits strong associated zonal wind variation in the downstream region, it may not entirely represent the zonal wind variability over the eastern North Pacific, which is beyond the scope of the current analysis.

Beyond wintertime, we applied similar analyses to investigate dynamical processes responsible for the interannual variabilities of the East Asian jet in other seasons. We find that results regarding the wintertime variability are also representative for spring and fall, but not for summer. In spring and fall, intensifications of the East Asian jet can also be attributed to distinct up- and downstream controls, where tropical heating mainly controls the upstream and synoptic eddies mainly control the downstream. However, tropical heating over the Bay of Bengal-South China Sea becomes less important, leaving only the Western Pacific contributing to anomalous local Hadley Cells. Meridional displacements of the jet are still primarily attributed to anomalous transient eddy activities in East Asia-North Pacific. Moreover, signals in synoptic eddy activities are more zonally-prolonged and can extend to the northwest Pacific in transient seasons.

Acknowledgements We thank two anonymous reviewers for providing insightful feedback that greatly improves the quality of the paper. We also thank M.J. Fu for discussions. This study was supported by the National Key Research and Development Program under grant 2018YFC1506001, Strategic Priority Research Program of Chinese Academy of Sciences under grant XDA20100312, and National Natural Science Foundation of China under Grants 41675055, 41621005.

Open Access This article is licensed under a Creative Commons Attribution 4.0 International License, which permits use, sharing, adaptation, distribution and reproduction in any medium or format, as long as you give appropriate credit to the original author(s) and the source, provide a link to the Creative Commons licence, and indicate if changes were made. The images or other third party material in this article are included in the article's Creative Commons licence, unless indicated otherwise in a credit line to the material. If material is not included in the article's Creative Commons licence and your intended use is not permitted by statutory regulation or exceeds the permitted use, you will need to obtain permission directly from the copyright holder. To view a copy of this licence, visit http://creativecommons.org/licenses/by/4.0/. 


\section{References}

Athanasiadis PJ, Wallace JM, Wettstein J (2011) Patterns of wintertime jet stream variability and their relation to the storm tracks. $\mathbf{J}$ Atmos Sci 67:1361-1381

Cheung HH, Zhou W (2016) Simple metrics for representing east Asian winter monsoon variability: urals blocking and western Pacific teleconnection patterns. Adv Atmos Sci 33(6):695-705

Chowdary JS, Hu K, Srinivas G, Kosaka Y, Wang L, Rao KK (2019) The Eurasian jet streams as conduits for east Asian monsoon variability. Curr Clim Change Rep 20:1-12

Dee DP et al (2011) The era-interim reanalysis: configuration and performance of the data assimilation system. Q J R Meteorol Soc 137(656):553-597

Emery W, Thomson R (2001) Data analysis methods in physical oceanography. Elsevier Science, Oxford, p 638

Kalnay Et et al (1996) The NCEP/NCAR 40-year reanalysis project. Bull Am Meteorol Soc 77(3):437-471

Fang J, Yang X-Q (2016) Structure and dynamics of decadal anomalies in the wintertime midlatitude north Pacific oceanatmosphere system. Clim Dyn 47(5):1989-2007. https://doi. org/10.1007/s00382-015-2946-X

Fiorino M (2004) A multi-decadal daily sea surface temperature and sea ice concentration data set for the ERA-40 reanalysis. European Centre for Medium Range Weather Forecasts

Franzke C, Feldstein SB, Lee S (2011) Synoptic analysis of the Pacific-north American teleconnection pattern. Q J R Meteorol Soc 137(655):329-346

Gao S, Tao S (1991) Acceleration of uppertropospheric jet stream and lower-tropospheric frontogenesis. Chin J Atmos Soc $15: 11-21$

Gu S, Zhang Y, Wu Q, Yang X-Q (2018) The linkage between arctic sea ice and midlatitude weather: in the perspective of energy. J Geophys Res Atmos 123:11-536-11-550. https://doi. org/10.1029/2018JD028743

He J, Lin H, Wu Z (2011) Another look at influences of the MaddenJulian oscillation on the wintertime east Asian weather. J Geophys Res Atmos 116:D3

Held IM (1975) Momentum transport by quasi-geostrophic eddies. J Atmos Sci 32(7):1494-1497

Held IM, Hou AY (1980) Nonlinear axially symmetric circulations in a nearly inviscid atmosphere. J Atmos Sci 37(3):515-533

Hirahara S, Ishii M, Fukuda Y (2014) Centennial-scale sea surface temperature analysis and its uncertainty. J Clim 27(1):57-75

Hoskins BJ, James IN, White GH (1983) The shape, propagation and mean-flow interaction of large-scale weather systems. J Atmos Sci 40(7):1595-1612

Huang J, Zhang Y, Yang X-Q, Ren X, Hu H (2020) Impacts of North Pacific subtropical and subarctic oceanic frontal zones on the wintertime atmospheric large-scale circulations. J Clim. https://doi. org/10.1175/JCLI-D-19-0308.1

Jhun J-G, Lee E-J (2004) A new east Asian winter monsoon index and associated characteristics of the winter monsoon. J Clim 17(4):711-726

Kiehl JT, Trenberth KE (1997) Earth's annual global mean energy budget. Bull Am Meteorol Soc 78(2):197-208

Lee S, Kim H-K (2003) The dynamical relationship between subtropical and eddy-driven jets. J Atmos Sci 60(12):1490-1503

Leung MY-T, Zhou W (2015) Variation of circulation and east Asian climate associated with anomalous strength and displacement of the east Asian trough. Clim Dyn 45(9-10):2713-2732

Leung MY-T, Zhou W (2016) Eddy contributions at multiple timescales to the evolution of persistent anomalous east Asian trough. Clim Dyn 46(7-8):2287-2303
Li C, Wettstein JJ (2012) Thermally driven and eddy-driven jet variability in reanalysis*. J Clim 25(5):1587-1596

Li Y, Yang S (2010) A dynamical index for the east Asian winter monsoon. J Clim 23(15):4255-4262

Liang X-Z, Wang W-C (1998) Associations between China monsoon rainfall and tropospheric jets. Q J R Meteorol Soc 124(552):2597-2623

Liao Z, Zhang Y (2013) Concurrent variation between the East Asian subtropical jet and polar front jet during persistent snow storm period in 2008 winter over southern China. J Geophys Res Atmos 118:6360-6373

Lindzen RS, Hou AV (1988) Hadley circulations for zonally averaged heating centered off the equator. J Atmos Sci 45(17):2416-2427

Liu Y, Wang L, Zhou W, Chen W (2014) Three eurasian teleconnection patterns: spatial structures, temporal variability, and associated winter climate anomalies. Clim Dyn 42(11-12):2817-2839

Lorenzo ED et al (2008) North Pacific gyre oscillation links ocean climate and ecosystem change. Geophys Res Lett 35(8):1-6

Mantua NJ, Hare SR, Zhang Y, Wallace JM, Francis RC (1997) A Pacific interdecadal climate oscillation with impacts on salmon production. Bull Am Meteorol Soc 78(6):1069-1079

Martius O (2014) A lagrangian analysis of the northern hemisphere subtropical jet. J Atmos Sci 71:2354-2369

Overland J, Francis JA, Hall R, Hanna E, Kim S-J, Vihma T (2015) The melting Arctic and Midlatitude weather patterns: are they connected? J Clim 28(20):7917-7932. https://doi.org/10.1175/ jcli-d-14-00822.1

Palmén E, Newton CW (1969) Atmospheric circulation systems: their structure and physical interpretation. Academic Press, New York, p 603

Panetta RL (1993) Zonal jets in wide baroclinically unstable regions: persistence and scale selection. J Atmos Sci 50(14):2073-2106

Ren X, Zhang Y, Xiang Y (2008) Connections between wintertime jet stream variability, oceanic surface heating, and transient eddy activity in the North Pacific. J Geophys Res Atmos 113:D21

Ren X, Yang X, Chu C (2010) Seasonal variations of the synopticscale transient eddy activity and polar front jet over East Asia. J Clim 23(12):3222-3233

Ren X, Yang X, Zhou T, Fang J (2011) Diagnostic comparison of wintertime East Asian subtropical jet and polar-front jet: largescale characteristics and transient eddy activities. Acta Meteorol Sin 25(1):21-33

Schiemann R, Lüthi D, Schär C (2009) Seasonality and interannual variability of the westerly jet in the Tibetan Plateau region. J Clim 22(11):2940-2957

Shapiro MA, Keyser DA (1990) Fronts, jet streams, and the tropopause. Extratropical cyclones. In: Newton C, Holopainen E (eds) Palmén memorial volume, vol 10. American Meteorology Society, Boston, pp 167-191

Takaya K, Nakamura H (2001) A formulation of a phase-independent wave-activity flux for stationary and migratory quasigeostrophic eddies on a zonally varying basic flow. J Atmos Sci 58(6):608-627

Wallace JM, Gutzler DS (1981) Teleconnections in the geopotential height field during the northern hemisphere winter. Mon Weather Rev 109(4):784-812

Wang L, Chen W (2014) An intensity index for the east Asian winter monsoon. J Clim 27(6):2361-2374

Wang L, Lu M-M (2017) The east Asian winter monsoon. Research and forecast. The global monsoon system. World Scientific, Singapore, pp 51-61

Wang W, Zhou W, Wang X, Fong SK, Leong KC (2013) Summer high temperature extremes in Southeast China associated with the East Asian jet stream and circumglobal teleconnection. J Geophys Res Atmos 118(15):8306-8319 
Wang L, Yang X-Q, Yang D, Xie Q, Fang J, Sun X (2017) Two typical modes in the variabilities of wintertime north Pacific basin-scale oceanic fronts and associated atmospheric eddy-driven jet. Atmos Sci Lett 18(9):373-380

Wettstein J, Wallace JM (2010) Observed patterns of month-to-month storm-track variability and their relationship to the background flow. J Atmos Sci 67:1420-1437

Xiao B, Zhang Y, Yang X-Q, Nie Y (2016) On the role of extratropical air-sea interaction in the persistence of the southern annular mode. Geophys Res Lett 43(16):8806-8814. https://doi. org/10.1002/2016GL070255

Xie P, Arkin PA (1997) Global precipitation: a 17-year monthly analysis based on gauge observations, satellite estimates, and numerical model outputs. Bull Am Meteorol Soc 78(11):2539-2558

Yang S, Lau K, Kim K (2002) Variations of the East Asian jet stream and Asian-Pacific-American winter climate anomalies. J Clim 15(3):306-325

Yang J, Liu Q, Liu Z (2010) Linking observations of the Asian Monsoon to the Indian Ocean SST: possible roles of Indian Ocean basin mode and dipole mode. J Clim 23:5889-5902

Yeh T-C, Tao S, Li M (1959) The abrupt change of circulation over the Northern Hemisphere during June and October. Atmos Sea Motion 20:249-267
Zhang Y, Stone P (2011) Baroclinic adjustment in an atmosphere-ocean thermally coupled model: the role of the boundary layer processes. J Atmos Sci 68:2710-2730

Zhang Y, Wang D, Ren X (2008) Seasonal variation of the meridional wind in the temperate jet stream and its relationship to the Asian Monsoon. Acta Meteorol Sin 22(4):446-454

Zhang Y, Zou T, Xue Y (2019) An Arctic-Tibetan connection on subseasonal to seasonal time scale. Geophys Res Lett 46:2790-2799. https://doi.org/10.1029/2018GL081476. https://agupubs.onlin elibrary.wiley.com/doi/abs/10.1029/2018GL081476

Zheng J, Liu Q, Wang C, Zheng X-T (2013) Impact of heating anomalies associated with rainfall variations over the Indo-Western Pacific on Asian atmospheric circulation in winter. Clim Dyn 40:2023-2033

Publisher's Note Springer Nature remains neutral with regard to jurisdictional claims in published maps and institutional affiliations. 